\title{
Membrane system design for multicomponent gas mixtures via mixed-integer nonlinear programming
}

\author{
Runhong Qi ${ }^{1}$, Michael A. Henson * \\ Department of Chemical Engineering, Louisiana State University, Baton Rouge, LA 70803-7303, USA \\ Received 4 April 1999; received in revised form 24 August 2000; accepted 24 August 2000
}

\begin{abstract}
An optimal design strategy for membrane networks separating multicomponent gas mixtures based on an approximate permeator model and mixed-integer nonlinear programming (MINLP) is proposed. A permeator system superstructure is used to embed a very large number of possible network configurations and allows the permeator feed-side pressure to be fixed or a design variable. A MINLP design model is developed to minimize the total annual process cost by simultaneous optimization of the permeator configuration and operating conditions. Case studies for the separation of acid gases $\left(\mathrm{CO}_{2}\right.$ and $\left.\mathrm{H}_{2} \mathrm{~S}\right)$ from crude natural gas mixtures with spiral-wound permeators are presented. Permeator configurations are derived for different number of separation stages for both continuous and discrete membrane areas. The method is sufficiently robust to handle product compositions that vary five orders of magnitude. The proposed approach provides an efficient methodology for preliminary screening of multi-stage membrane separation systems for multicomponent gas mixtures. (C) 2000 Elsevier Science Ltd. All rights reserved.
\end{abstract}

Keywords: Gas separations; Permeators; Process design; Mixed-integer nonlinear optimization

\section{Introduction}

Membrane systems have become viable alternatives to conventional gas separation technologies such as pressure swing adsorption and cryogenic distillation. The economics of membrane separation processes depend critically on process design. The design of a membrane system consists of two subproblems: (i) selection of an appropriate permeator configuration; and (ii) determination of the operating conditions of the individual permeators. Membrane systems currently are designed via a sequential procedure in which the permeator configuration is chosen a priori and the operating conditions are determined using some type of optimization procedure. Many design studies for multi-stage gas membrane systems are based on this approach. Spillman, Barrett and Cooley (1988) investigate several permeator configurations for the separation of $\mathrm{CO}_{2} / \mathrm{CH}_{4}$

\footnotetext{
* Corresponding author. Tel.: +1-225-3883690; fax: + 1-2253881476.

E-mail address: henson@che.lsu.edu (M.A. Henson).

${ }^{1}$ Present address: Dynamic Optimization Technology (DOT) Products Inc., 11490 Westheimer, Suite 810, Houston, TX 77077, USA.
}

mixtures encountered in natural gas treatment and enhanced oil recovery. Babcock, Spillman, Goddin and Cooley (1988) evaluate the economics of single- and three-stage membrane systems for natural gas treatment by providing comparisons with amine treatment processes. Bhide and Stern propose a grid search method to design membrane separation systems for natural gas treatment (Bhide \& Stern, 1993a,b) and oxygen enrichment of air (Bhide \& Stern, 1991a,b). Xu and Agrawal (1996), Agrawal (1997), Agrawal and Xu (1996a,b) develop a stepwise procedure for design of membrane cascades using a limited number of recycle compressors.

The sequential design approach is well suited for detailed evaluation of a small number of alternative flowsheets. However, the lack of systematic methodologies for selecting the candidate permeator configurations restricts this approach to experienced design engineers. Another potential shortcoming is that the final flowsheet may be suboptimal because the enumeration and evaluation of all reasonable network configurations is infeasible. Consequently, there is considerable motivation to develop more systematic flowsheet optimization techniques for multi-stage gas membrane separation systems. 
A wide range of process design problems can be posed as mixed-integer nonlinear programming (MINLP) problems that allow simultaneous optimization of the process configuration and operating conditions (Floudas, 1995). This mathematical framework has been utilized to solve process synthesis problems for heat exchanger networks, distillation column sequences, reactor networks, and mass-exchange networks (Floudas, 1995; Floudas \& Grossmann., 1994; Grossmann \& Kravanja, 1995; Grossmann \& Daichendt, 1996). The most common approach is to postulate a superstructure that embeds many process configurations, each of which is a candidate for the optimal process flowsheet. The superstructure is mathematically described by a model that contains both continuous and integer variables that represent operating conditions, as well as processing units and their interconnections. The MINLP model is posed as a set of constraints in an appropriate optimization problem. Several algorithms for solving the resulting MINLP problems have been developed (Floudas, 1995). The most widely used is DICOPT ++ (Viswanathan \& Grossmann, 1990) within the General Algebraic Modeling System (GAMS; Brooke, Kendrick \& Meeraus, 1992). Recently, there have been many advances in algorithm development for global optimization of nonconvex MINLP problems (Grossmann \& Daichendt, 1996; Adjiman, Androulakis \& Floudas, 1997).

For gas membrane separation systems, a major difficulty in developing MINLP synthesis techniques is that fundamental permeator models are comprised of differential-algebraic-integral equations with mixed boundary conditions. Multicomponent permeator models are particularly difficult to use for MINLP design due to their computational complexity. An alternative approach is to utilize approximate models that provide a more reasonable compromise between prediction accuracy and computational efficiency. Recently, we proposed an approximate modeling technique for spiral-wound permeators separating binary (Qi \& Henson, 1996) and multicomponent (Qi \& Henson, 1997) gas mixtures. The model development involves the application of simplifying assumptions to basic transport models that include permeate-side pressure drop. The resulting models are well suited for process design because the nonlinear algebraic equations can be solved very efficiently and yield excellent prediction accuracy over a wide range of operating conditions. We have utilized the binary model to develop a MINLP design technique for multi-stage membrane systems that allows simultaneous optimization of the permeator network and operating conditions (Qi \& Henson, 1998a).

In this paper, we solve the more challenging and industrially important problem of MINLP design of multi-stage membrane systems for multicomponent gas mixtures. The permeator system superstructure allows the feed-side pressure to be fixed or a design variable. The optimal design strategy is applied to spiral-wound membrane systems separating acid gases $\left(\mathrm{CO}_{2}\right.$ and $\left.\mathrm{H}_{2} \mathrm{~S}\right)$ from crude natural gas mixtures in natural gas treatment and enhanced oil recovery.

\section{Optimal design strategy}

\subsection{Problem statement}

The problem of designing membrane systems for multicomponent gas separations can be stated as:

Given a feed mixture of known conditions, synthesize the minimum cost network of membrane permeators and recycle compressors that separate the feed stream into two products of specified composition. The membrane properties and cost related parameters are assumed to be known.

The design task involves the determination of the optimal system configuration, as well as specification of the process unit sizes and operating conditions. It is necessary to derive a permeator system superstructure that embeds all network configurations of practical interest, formulate the superstructure as a MINLP model and develop a suitable solution methodology. The optimal design strategy is based on the following assumptions:

1. The feed stream contains a multicomponent gas mixture at known conditions.

2. The feed-side pressure drop is negligible for each permeation stage.

3. There is no pressure drop between permeation stages.

4. The product permeate stream pressure is predetermined, while the permeate stream pressures between stages are design variables.

5. All permeators and compressors operate under isothermal conditions.

It is possible to relax some of these assumptions at the expense of a more complex MINLP model.

\subsection{Multicomponent permeator model}

The MINLP design strategy requires a robust and computationally efficient model of a multicomponent gas permeator. In Appendix A, we present an approximate model for spiral-wound permeators that is derived directly from the fundamental transport equations by assuming the residue flow rate to be constant in the direction of permeate flow. A detailed justification of this assumption is available elsewhere (Qi \& Henson, 1997). The multicomponent model contains initial value 
differential equations for the feed-side flow rate and permeate concentrations on the membrane surface that are not present in the binary case. These equations are reduced to algebraic equations using a fourth-order Runge-Kutta-Gill algorithm. As a result of these equations and the multicomponent mass balances, the resulting algebraic design model is substantially more complex than its binary counterpart (Qi \& Henson, 1996). We have shown that the approximate multicomponent model compares favorably with the fundamental transport model in terms of prediction accuracy. The major advantage of the approximate model is that the nonlinear algebraic equations can be solved 200 700 times faster than the basic transport model equations (Qi \& Henson, 1997).

\subsection{Permeator system superstructure}

The superstructure approach to process design provides a systematic framework for simultaneous optimization of the process configuration and operating conditions (Floudas, 1995). Superstructures have been proposed for a number of membrane separation systems, including reverse osmosis (Zhu, El-Halwagi \& Al-Ahmad, 1997) and pervaporation (Srinivas \& ElHalwagi, 1993) networks. For gas separation systems, the basic components of the superstructure are permeators, compressors, stream mixers and stream splitters. The superstructure for multicomponent membrane separation systems is derived as described below. Note that each separation stage may comprise several permeators in parallel.

1. The fresh feed stream is compressed if a higher feed-side operating pressure is needed.

2. The fresh feed stream is split into individual feed streams for each permeation stage.
3. The inlet stream to a particular stage consists of its individual fresh feed stream; recycle streams obtained from the permeator's effluent streams; and recycle streams obtained from the effluent streams of all other stages.

4. For each stage the permeate and residue streams are split into recycle streams for the particular stage; recycle streams for all other stages; and streams that are sent to the final product mixers. The permeate recycle streams must be compressed to the feed pressure before being sent to the feed stream mixers.

5. The inlet streams for the final permeate (residue) mixer are obtained from the permeate (residue) streams of all stages.

As an illustration, the superstructure for three separation stages is shown in Fig. 1. This superstructure is capable of representing a very large number of permeator configurations, each of which is a candidate for the optimal flowsheet. Superstructures containing different number of separation stages are developed similarly.

\subsection{Mathematical formulation}

The permeator system superstructure is modeled as the following MINLP problem:

$\min : c Z+f(X)$

s.t.: $U_{1} Z+h(X)=0$

$U_{2} Z+g(X) \leq 0$

$X \in R^{n}$

$Z \in\{0,1\}^{l}$

where $X$ is a vector of $n$ continuous variables that represent flow rates, pressures and compositions of the process streams, as well as continuous properties of the

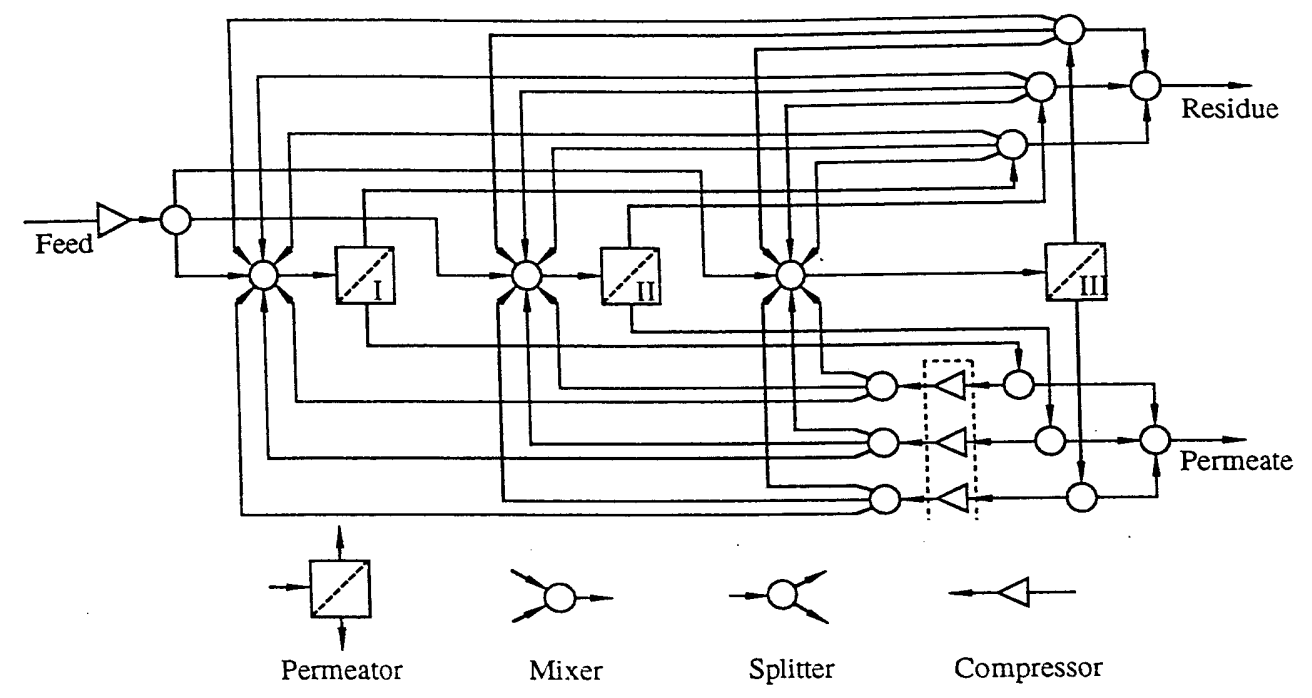

Fig. 1. Permeator system superstructure with three permeation stages. 
process units; $Z$ is a vector of $l$ binary variables that denote the existence $\left(Z_{i}=1\right)$ or nonexistence $\left(Z_{i}=0\right)$ of process units and connections, as well as discrete properties of the process units; $c Z+f(X)$ is an objective function that represents the annual cost of the membrane system; $U_{1} Z+h(X)$ are $\mathrm{m}$ equality constraints that denote permeator model equations and other material balances; and $U_{2} Z+g(X)$ are $p$ inequality constraints that correspond to separation requirements, operational restrictions and logical constraints. Note that all the binary variables appear linearly, while the continuous variables may appear nonlinearly in the functions $f(X), g(X)$, and $h(X)$.

\subsubsection{Annual process cost}

The optimal design of a membrane system entails a tradeoff between capital investments and operating expenses. The annual process cost should take into account capital investments associated with permeators and compressors, as well as operating expenses due to replacement of membrane elements, maintenance, consumption of utilities and product losses. We utilize the approximate costing procedures presented by Spillman, Barrett and Cooley (1988) and Babcock et al. (1988) for removal of acid gases from natural gas mixtures. It is important to emphasize that this method only provides an estimate of the annual process cost. As a result, the MINLP design strategy is most appropriate for deriving flowsheets that can be subjected to more detailed analysis. The mathematical formulation of the process cost function is shown in Appendix B.

\subsubsection{Constraints}

The annual process cost is minimized subject to following types of constraints,

1. material balance constraints;

2. permeator model constraints;

3. composition sum constraints;

4. operating requirement constraints;

5. logic constraints;

6. discrete membrane area constraints;

7. nonnegativity and integrality constraints.

Detailed mathematical formulation of the constraint equations is presented in Appendix C. Solution of the MINLP model provides the optimal system configuration and unit sizes, as well as optimal operating conditions for the individual streams.

\subsection{Solution strategy}

The MINLP design model is solved using the algorithm of Viswanathan and Grossmann (1990), which is available in the General Algebraic Modeling System (GAMS; Brooke et al., 1992) as the solver DICOPT + + . The MINLP problem is decomposed into a series of nonlinear program (NLP) and MILP subproblems us- ing an outer approximation formulation (Quesada \& Grossmann, 1992). These subproblems can be solved using any NLP and MILP solvers that run in the GAMS environment. In this paper, CONOPT2 is used for the NLP problem and XA is used for the MILP problem. It is important to note that the MINLP problem is nonconvex due to the nonlinear constraint equations. As a result, the solution obtained represents only a local optimum. We address this problem by initializing the variables at several different points, setting reasonable bounds on the variables, and adjusting the DICOPT ++ options to facilitate convergence to the global optimum. However, there is no guarantee that the global optimum will be found using this procedure.

\section{Case studies}

The MINLP design strategy is used to derive optimal spiral-wound permeator networks for acid gas separations in natural gas treatment and enhanced oil recovery. The crude natural gas can be regarded as a binary mixture $\left(\mathrm{CO}_{2}\right.$ and $\left.\mathrm{CH}_{4}\right)$, a four-component mixture $\left(\mathrm{CO}_{2}, \mathrm{H}_{2} \mathrm{~S}, \mathrm{CH}_{4}\right.$ and heavier hydrocarbons $\left.\mathrm{C}^{+} \mathrm{H}\right)$ or a five-component mixture $\left(\mathrm{CO}_{2}, \mathrm{H}_{2} \mathrm{~S}, \mathrm{CH}_{4}, \mathrm{C}_{2} \mathrm{H}_{6}\right.$ and heavier hydrocarbons $\mathrm{C}_{2}^{+} \mathrm{H}$ ) depending on the natural gas composition and accuracy requirements. We do not include $\mathrm{N}_{2}$ as a separate component because the permeabilities of $\mathrm{N}_{2}$ and $\mathrm{CH}_{4}$ in cellulose acetate membrane are very similar (Lee, Feldkirchner, Stern, Houde, Gamez \& Meyer, 1995; Ettouney, Al-Enezi \& Hughes, 1995). We investigate multi-stage permeator system design with different number of components while allowing the membrane area to be either a continuous variable or a discrete variable. The feed-side pressure is fixed or considered to be a design variable with an upper limit.

The nominal economic parameters and operating conditions in Table 1 are obtained from Babcock et al. (1988), Spillman et al. (1988), Lee and Feldkirchner (1993) and Lee et al. (1995). The gas volumes are calculated at standard conditions of $0.102 \mathrm{MPa}$ and 273 $\mathrm{K}$. The pressure parameter $C^{\prime \prime}$ is an estimated value from experimental data (Qi \& Henson 1996). The permeability coefficients used in this study have been derived from available sources (Pan, 1986; Ettouney et al., 1995; Lee et al., 1995). These values are consistent with data presented in the more recent literature (Bhide, Voskericyan \& Stern, 1998).

\subsection{Two-component mixture}

In our previous work on binary gas separations (Qi \& Henson, 1996), an MINLP design strategy was developed using an approximate permeator model. We have 
Table 1

Nominal operating conditions and economic parameters

\begin{tabular}{|c|c|c|}
\hline \multirow{5}{*}{$\begin{array}{l}\text { Operating } \\
\text { conditions }\end{array}$} & $U_{\mathrm{f} 00}$ & $10 \mathrm{~mol} / \mathrm{s}\left(19353 \mathrm{~m}^{3} /\right.$ day $)$ \\
\hline & $p_{\text {out }}$ & $0.105 \mathrm{Mpa}$ \\
\hline & $T$ & $40^{\circ} \mathrm{C}$ \\
\hline & $P_{\mathrm{f}}$ & Specified in text \\
\hline & $x_{\mathrm{f} 0}$ & Specified in text \\
\hline \multirow{3}{*}{$\begin{array}{l}\text { Operating } \\
\text { requirements }\end{array}$} & $x_{\mathrm{out}, \mathrm{CO}_{2}}$ & $\leq 2 \%$ \\
\hline & $y_{\text {out }, \mathrm{CH}_{4}}$ & $\leq 5 \%$ (for EOR) \\
\hline & $p_{\text {out }}$ & $0.105 \mathrm{MPa}$ \\
\hline \multirow{7}{*}{$\begin{array}{l}\text { Membrane } \\
\text { properties }\end{array}$} & $Q_{\mathrm{b}} / d\left(\mathrm{CH}_{4}\right)$ & $1.48 \times 10^{-3} \mathrm{~mol} / \mathrm{MPa} \mathrm{m} \mathrm{m}^{2} \mathrm{~s}$ \\
\hline & $\alpha\left(\mathrm{CO}_{2} / \mathrm{CH}_{4}\right)$ & 20 (All cases) \\
\hline & $\alpha\left(\mathrm{H}_{2} \mathrm{~S} / \mathrm{CH}_{4}\right)$ & $\begin{array}{l}16 \text { (Four- and five-component } \\
\text { cases) }\end{array}$ \\
\hline & $\alpha\left(\mathrm{C}^{+} \mathrm{H} / \mathrm{CH}_{4}\right)$ & 0.4 (Four-component case) \\
\hline & $\alpha\left(\mathrm{C}_{2} \mathrm{H}_{6} / \mathrm{CH}_{4}\right)$ & 0.4 (Five-component case) \\
\hline & $\alpha\left(\mathrm{C}_{2}^{+} \mathrm{H} / \mathrm{CH}_{4}\right)$ & 0.1 (Five-component case) \\
\hline & $C^{\prime \prime}$ & $9.32 \mathrm{MPa}^{2} \mathrm{~m}^{2} \mathrm{~s} / \mathrm{mol}$ \\
\hline \multirow{5}{*}{$\begin{array}{l}\text { Capital } \\
\text { investment }\end{array}$} & $f_{\mathrm{mh}}$ & $200 \$ / \mathrm{m}^{2}$ membrane \\
\hline & $f_{\mathrm{cp}}$ & $1000 \$ / \mathrm{kW}$ \\
\hline & $\eta_{\mathrm{cp}}$ & $70 \%$ \\
\hline & $f_{\mathrm{wk}}$ & $10 \%$ of fixed capital \\
\hline & $f_{\mathrm{cc}}$ & $27 \%$ per year \\
\hline \multirow{6}{*}{$\begin{array}{l}\text { Operating } \\
\text { expenses }\end{array}$} & $f_{\mathrm{mr}}$ & $90 \$ / \mathrm{m}^{2}$ membrane \\
\hline & $T_{\mathrm{m}}$ & 3 years \\
\hline & $f_{\mathrm{mt}}$ & $5 \%$ of fixed capital $/$ year \\
\hline & $t_{\mathrm{wk}}$ & 300 days/year \\
\hline & $f_{\mathrm{sg}}$ & $35 \$ / \mathrm{km}^{3}$ \\
\hline & $f_{\mathrm{hv}}$ & $43 \mathrm{MJ} / \mathrm{m}^{3}$ \\
\hline
\end{tabular}

shown that this binary model and the approximate multicomponent model utilized here yield virtually identical predictions for binary gas mixtures and singlestage permeation systems (Qi \& Henson, 1997). It is useful to determine if the multicomponent MINLP design strategy proposed here reduces to the binary formulation when applied to binary separation problems. To this end, we have compared the two MINLP strategies for the design of three-stage systems for binary $\mathrm{CH}_{4} / \mathrm{CO}_{2}$ separations in natural gas treatment and enhanced oil recovery. Although not shown here for the sake of brevity, the resulting flowsheets are identical except for very small differences in operating conditions. Of course the multicomponent formulation is not computationally efficient for binary separations due to the complexity of the associated permeator model.

\subsection{Four-component mixture}

We assume that the natural gas mixture is composed of $\mathrm{CO}_{2}, \mathrm{H}_{2} \mathrm{~S}, \mathrm{CH}_{4}$, and heavier hydrocarbons $\mathrm{C}^{+} \mathrm{H}$. The fresh feed composition is $19.0 \% \mathrm{CO}_{2}, 1.0 \% \mathrm{H}_{2} \mathrm{~S}$,
73.0\% $\mathrm{CH}_{4}$ and $7.0 \% \mathrm{C}^{+} \mathrm{H}$, and the fresh feed pressure is $3.5 \mathrm{MPa}$. These conditions are representative of actual applications (Lee \& Feldkirchner, 1993; Lee et al., 1995). As discussed earlier, $\mathrm{N}_{2}$ is not included explicitly because it has the same permeability as $\mathrm{CH}_{4}$ in cellulose acetate membrane. The permeator feed-side pressure is taken as the fresh feed pressure. We apply the MINLP design strategy to design membrane systems for both natural gas treatment and enhanced oil recovery applications.

For natural gas treatment, the $\mathrm{CO}_{2}$ concentration of the residue product must be no greater than $2 \%$ to produce pipeline grade gas. No concentration constraint is placed on the permeate stream because it is a low-grade fuel or a waste gas. Flowsheets with two and three separation stages that minimize the annual process cost are synthesized. A configuration with continuous membrane area provides a lower bound on the annual cost for a particular number of separation stages. A configuration with discrete membrane area generally will yield a higher process cost, but the resulting flowsheet is more realistic since vendors offer membrane area in discrete increments.

The optimal flowsheet for a two-stage system with continuous membrane area is shown in Fig. 2. The corresponding flowsheet for a discrete membrane element area of $20 \mathrm{~m}^{2}$ is shown in Fig. 3. Note that both flowsheets satisfy the $2 \% \mathrm{CO}_{2}$ purity constraint placed on the product residue stream. While the system configurations for the two cases are identical, the operating conditions are significantly different. The total membrane area changes only slightly, but the membrane area for each individual stage is quite different. The total compressor power and $\mathrm{CH}_{4}$ recovery differ because of the different distribution of membrane area. As expected, the process cost for the discrete area case is slightly higher than that obtained for the continuous area case.

Fig. 4 shows the optimal flowsheet for a three-stage system with continuous membrane area. This design represents a slight modification of the two-stage configuration (Fig. 2) in which a small third-stage permeator is used to separate the second-stage permeate stream. The total process cost is slightly lower than that of the two-stage system because of increased $\mathrm{CH}_{4}$ recovery. The optimal flowsheet for a three-stage system with discrete membrane element area of $20 \mathrm{~m}^{2}$ is shown in Fig. 5. The system configuration is different from that obtained for the continuous area case (Fig. 4) in that the third-stage residue stream recycles to the second stage rather than to the first stage. Even though the process costs for the two configurations are quite close, the distributions of membrane area and $\mathrm{CH}_{4}$ recoveries are significantly different. As a result, the flow rates and compositions of the product streams differ between the two cases. We have performed a 


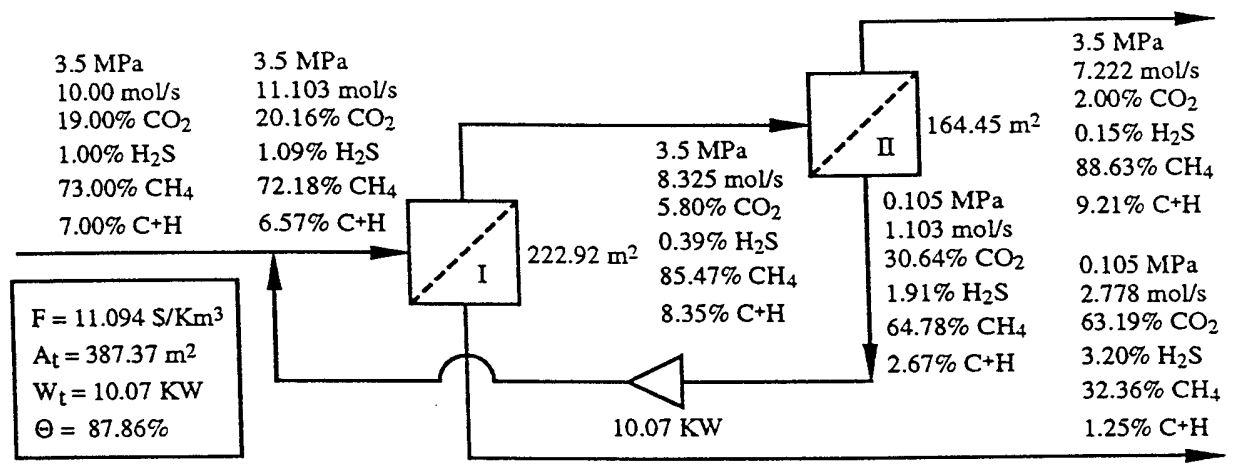

Fig. 2. Two-stage, four-component system with continuous membrane area (natural gas treatment).

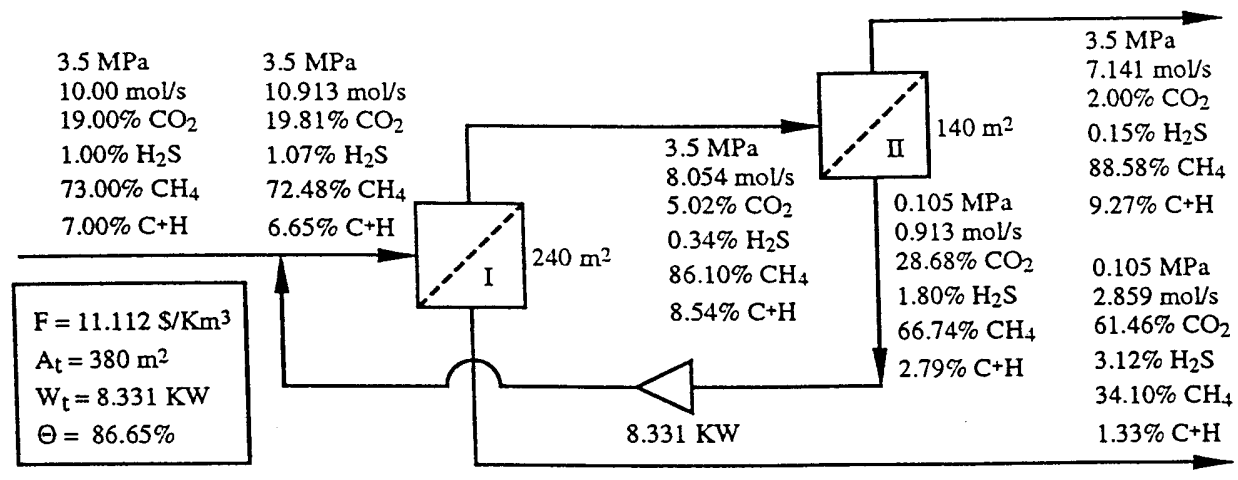

Fig. 3. Two-stage, four-component system with membrane element area of $20 \mathrm{~m}^{2}$ (natural gas treatment).

consistency check of the flowsheets in Figs. 4 and 5 by using NLP to determine the optimal unit sizes and operating conditions when the flowsheet is constrained appropriately. Although not shown here, the NLP generated flowsheets are identical to those synthesized via the MINLP strategy.

The significance of the configurational differences between Figs. 4 and 5 have been investigated by using NLP (Qi \& Henson, 1998b) to determine optimal flowsheets when the configuration is fixed to be that in Fig. 4 and the membrane areas are fixed at discrete values of 180,200 and $20 \mathrm{~m}^{2}$ (case 2); and the configuration is fixed to be that in Fig. 5 and the membrane area is allowed to vary continuously (case 3 ). Table 2 provides a comparison of the resulting flowsheets to those in Fig. 4 (case 1) and Fig. 5 (case 4). The configuration in Fig. 4 (case 1) has a slightly lower cost than does the configuration in Fig. 5 (case 3) when the membrane area is varied continuously. In contrast, the configuration in Fig. 5 (case 4) has a slightly lower cost than does the configuration in Fig. 4 (case 2) for a discrete membrane element area of $20 \mathrm{~m}^{2}$. These results suggest that the MINLP strategy is generating the optimal flowsheet for each scenario. Since the process costs for the four flowsheets differ only by a very small amount, both configurations should be judged as viable candi- dates for the final design. This illustrates the importance of sound engineering judgement in interpreting the MINLP synthesis results.

To check the optimality of the flowsheets in Figs. 2 and 4 , the system configuration is fixed and the resulting NLP is solved to determine the optimal unit sizes and operating conditions (Qi \& Henson, 1998b). The membrane area is treated as a continuous variable. Table 3 summarizes the results for the configurations shown in Fig. 6. Configuration $\mathrm{H}$ corresponds to the three-stage configuration shown in Fig. 4. A result for configuration $\mathrm{B}$ is not shown because it reduces to configuration A. Configuration D yields the lowest cost for the two-stage systems considered. This flowsheet is virtually identical to that derived for two separation stages using the MINLP strategy (Fig. 2). The lowest cost for three separation stages is obtained with configuration $\mathrm{H}$, which yields an identical flowsheet as that derived with the MINLP strategy for a three-stage system (Fig. 4). These results are consistent with the MINLP strategy generating the optimal flowsheets. Note that the two-stage configuration $\mathrm{D}$ and the threestage configurations $\mathrm{F}$ and $\mathrm{H}$ yield very similar costs. A possible explanation for this result is that the lack of a purity constraint on the permeate stream leads to an optimization problem that only is mildly constrained. This allows the total membrane area to be allocated 


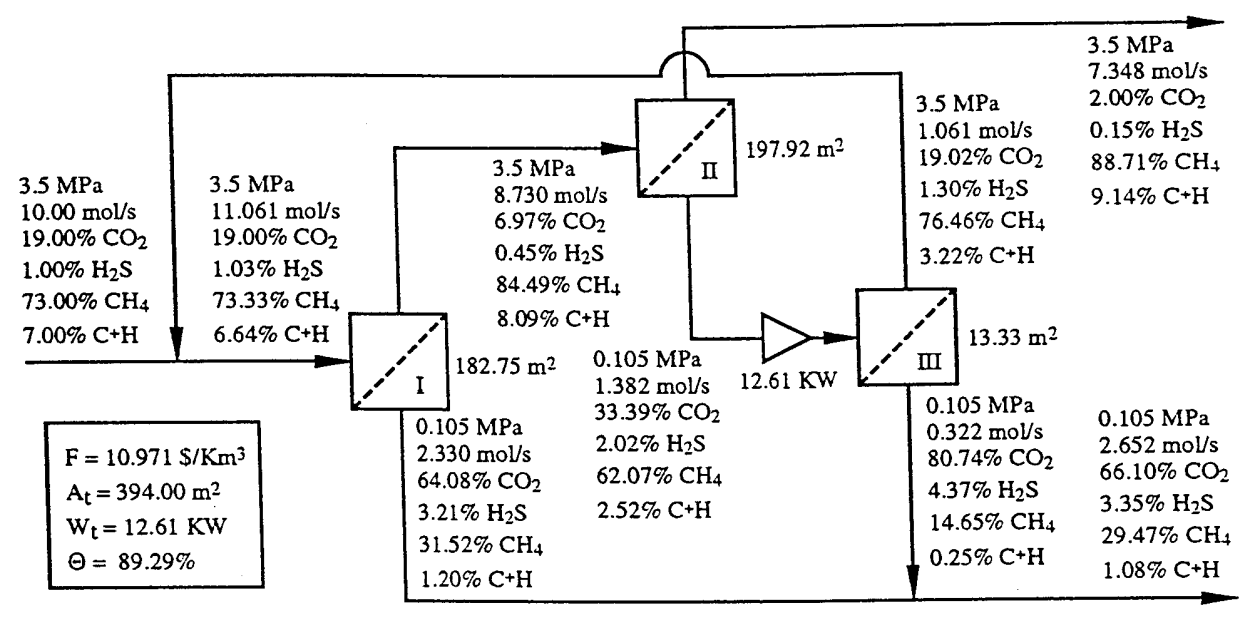

Fig. 4. Three-stage, four-component system with continuous membrane area (natural gas treatment).

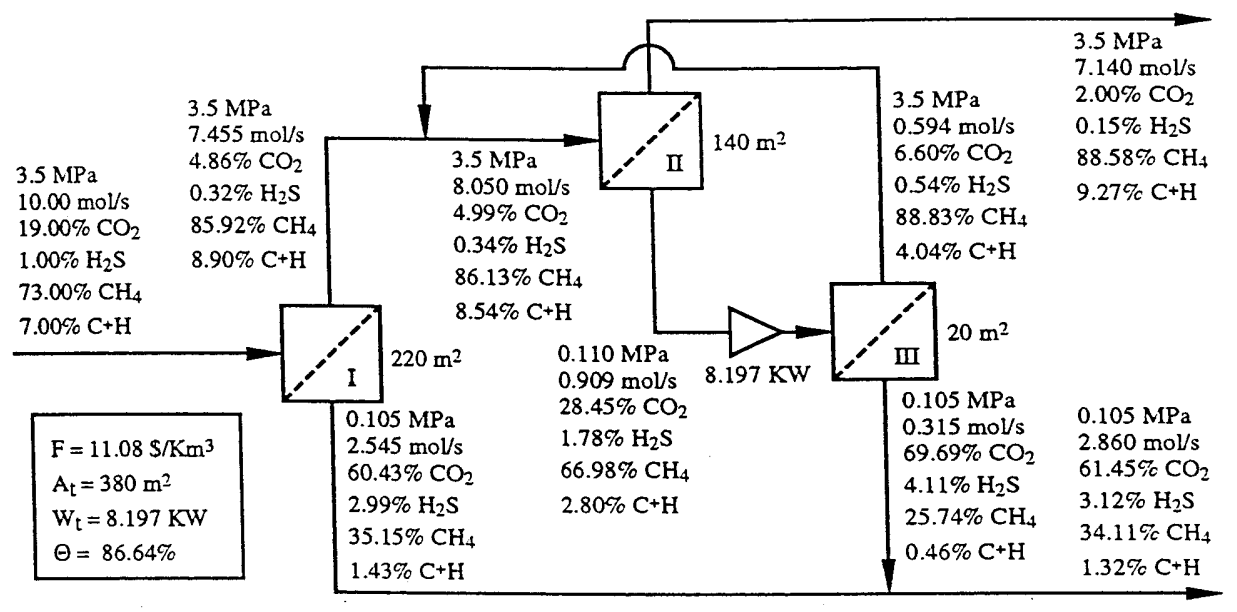

Fig. 5. Three-stage, four-component system with membrane element area of $20 \mathrm{~m}^{2}$ (natural gas treatment).

differently with similar overall process costs. Due to its simplicity, the two-stage configuration $\mathrm{D}$ would be preferred despite yielding a slightly higher process cost.

For acid gas separations in enhanced oil recovery, both the residue and permeate streams must satisfy composition constraints. Figs. 7 and 8 show the optimal designs for three- and four-stage systems, respectively, with a discrete membrane element area of $20 \mathrm{~m}^{2}$. Results for continuous membrane area are not presented for the sake of brevity. Increasing the number of membrane stages significantly decreases the process cost because the separation requirements on both the residue and permeate streams severely restrict the optimal flowsheet. This example demonstrates the advantage of investigating more than three separation stages, which is very difficult with sequential design procedures where the configurations are chosen a priori. Note that the residue product concentration of $\mathrm{H}_{2} \mathrm{~S}$ and permeate product concentration of $\mathrm{C}^{+} \mathrm{H}$ are very small compared with the major components $\mathrm{CH}_{4}$ and $\mathrm{CO}_{2}$.

Table 2

Effect of the discrete membrane area constraint on three-stage separation systems

\begin{tabular}{lcccc}
\hline Parameter & Case 1 & Case 2 & Case 3 & Case 4 \\
\hline $\begin{array}{l}\text { Membrane area I }\left(\mathrm{m}^{2}\right) \\
\text { Membrane area II } \\
\left(\mathrm{m}^{2}\right)\end{array}$ & 182.75 & 180 & 167.75 & 220 \\
$\begin{array}{l}\text { Membrane area III } \\
\left(\mathrm{m}^{2}\right)\end{array}$ & 13.33 & 200 & 195.95 & 140 \\
$\begin{array}{l}\text { Total membrane area } \\
\left(\mathrm{m}^{2}\right)\end{array}$ & 394.00 & 400 & 390.19 & 20 \\
$\begin{array}{l}\text { Compressor power } \\
(\mathrm{kW})\end{array}$ & 12.61 & 12.06 & 12.46 & 380 \\
$\begin{array}{l}\mathrm{CH} \\
\text { Annual procovery }(\%)\end{array}$ & 89.29 & 89.04 & 89.17 & 86.20 \\
$\quad\left(\$ \mathrm{~km}^{3}\right)$ & 10.97 & 11.10 & 10.99 & 11.08 \\
\hline
\end{tabular}


Table 3

Optimal flowheets for fixed process configurations

\begin{tabular}{lccccrrr}
\hline Parameter & A & C & D & E & F & G \\
\hline Membrane area I $\left(\mathrm{m}^{2}\right)$ & 349.97 & 141.41 & 222.91 & 409.35 & 167.75 & 317.98 \\
Membrane area II $\left(\mathrm{m}^{2}\right)$ & 0 & 202.92 & 164.47 & 70.15 & 195.95 & 96.12 \\
Membrane area III $\left(\mathrm{m}^{2}\right)$ & 0 & 0 & 0 & 0 & 30.19 & 61.37 & 197.92 \\
Total membrane area $\left(\mathrm{m}^{2}\right)$ & 349.97 & 344.33 & 387.37 & 479.50 & 393.90 & 475.47 & 394.00 \\
Compressor power $(\mathrm{kW})$ & 0 & 0 & 10.07 & 35.57 & 12.46 & 34.07 & 12.61 \\
$\mathrm{CH}_{4}$ recovery $(\%)$ & 80.00 & 80.37 & 87.68 & 96.81 & 89.17 & 97.34 \\
Annual process cost $\left(\$ / \mathrm{km}^{3}\right)$ & 11.78 & 11.58 & 11.09 & 12.35 & 10.99 & 11.99 & 10.97 \\
\hline
\end{tabular}

(a)

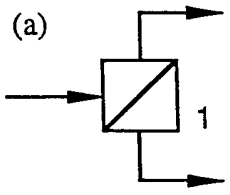

(b)

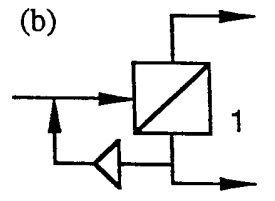

(d)

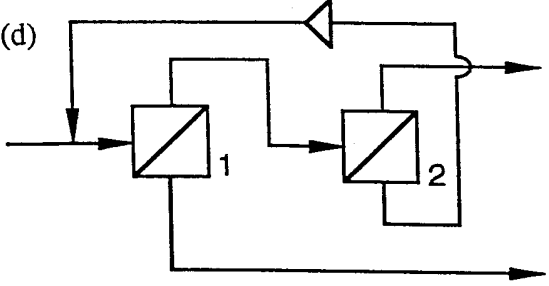

(f)

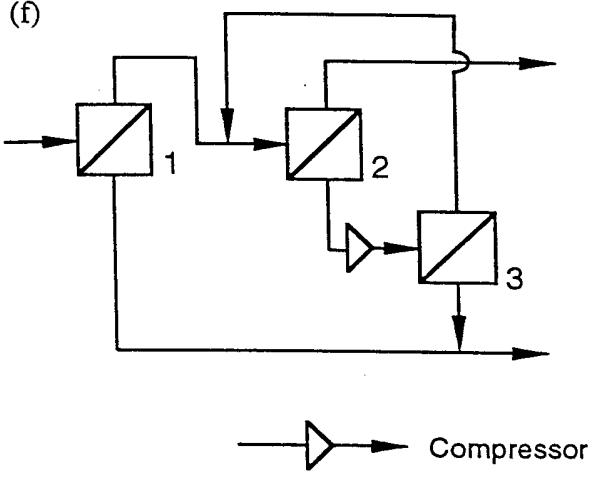

(c)

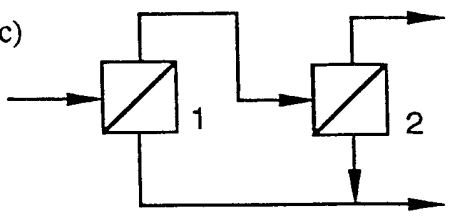

(e)

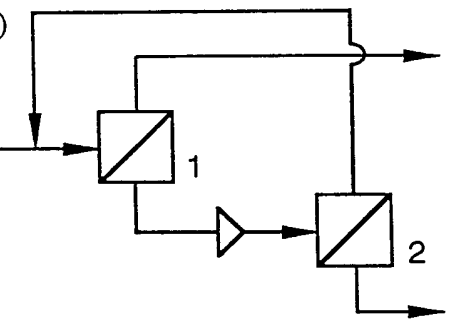

(g)
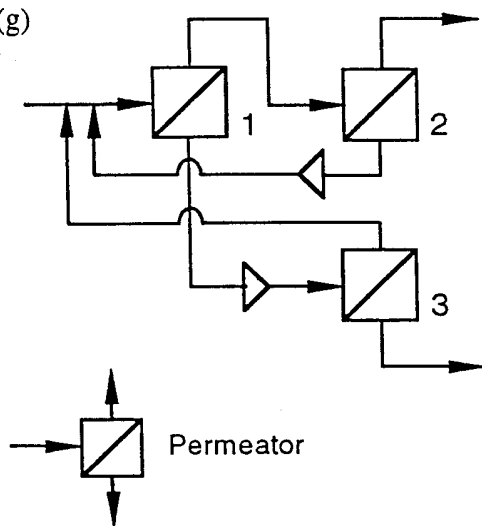

Fig. 6. Selected process configurations for optimality analysis (natural gas treatment).

\subsection{Five-component mixture}

The MINLP design strategy is applied to a five-component natural gas mixture to investigate its robustness for wider variations in membrane selectivities and stream compositions. We choose the feed compositions for a typical enhanced oil recovery application (Lee and Feldkirchner, 1993; Lee et al., 1995), 19.5\% $\mathrm{CO}_{2}, 0.5 \%$ $\mathrm{H}_{2} \mathrm{~S}, 73.0 \% \mathrm{CH}_{4}, 4.0 \% \mathrm{C}_{2} \mathrm{H}_{6}$ and $3.0 \%$ heavier hydrocarbons $\mathrm{C}_{2}^{+} \mathrm{H}$. The feed-side pressure is chosen as the fresh feed pressure (3.5 MPa). Figs. 9 and 10 show the optimal designs obtained for three-stage and four-stage systems, respectively, with continuous membrane area. The configuration in Fig. 9 is identical to that in Fig. 7, while the configuration in Fig. 10 is very similar to that in Fig. 8. Note that very small concentrations of $\mathrm{H}_{2} \mathrm{~S}$ in the residue products (about $0.08 \%$ ) and $\mathrm{C}_{2}^{+} \mathrm{H}$ in the permeate product (about $20 \mathrm{ppm}$ ) are obtained. These results indicate that the permeator design model and MINLP strategy are sufficiently robust to synthesize membrane systems in which component concentrations vary five orders of magnitude. 


\subsection{Optimization of feed-side pressure}

To generate the previous results, we assumed a relatively high fresh feed pressure and set the permeator feed-side pressure equal to this pressure. In some applications, optimization of feed-side pressure may be necessary to enhance process economics. An upper limit on the pressure must be imposed due to material and mechanical limitations of the equipment. The optimal feed-side pressure represents a trade-off between compressor power and total membrane area. We investigate feed-side pressure optimization by utilizing the feed stream compressor in the permeator system superstructure (Fig. 1). A four-component natural gas mixture $\left(19.0 \% \mathrm{CO}_{2}, 1.0 \% \mathrm{H}_{2} \mathrm{~S}, 73.0 \% \mathrm{CH}_{4}\right.$, and $\left.7.0 \% \mathrm{C}^{+} \mathrm{H}\right)$ is available at a low pressure $(0.105 \mathrm{MPa})$. The upper limit for the feed-side pressure is $5.0 \mathrm{MPa}$. Fig. 11 shows the optimal flowsheet for a three-stage configuration with continuous membrane area for natural gas treatment, while Fig. 12 shows the optimal four-stage flowsheet with continuous membrane area for enhanced oil recovery. In each case, a relatively large fresh feed compressor is needed but the configurations are identical to those generated in the absence of feed pressure optimization (Figs. 5 and 8). The feed-side pressure goes to the upper limit for the economic parameters chosen; a lower pressure may be obtained for different economic parameters. Note from Fig. 12 that the super-

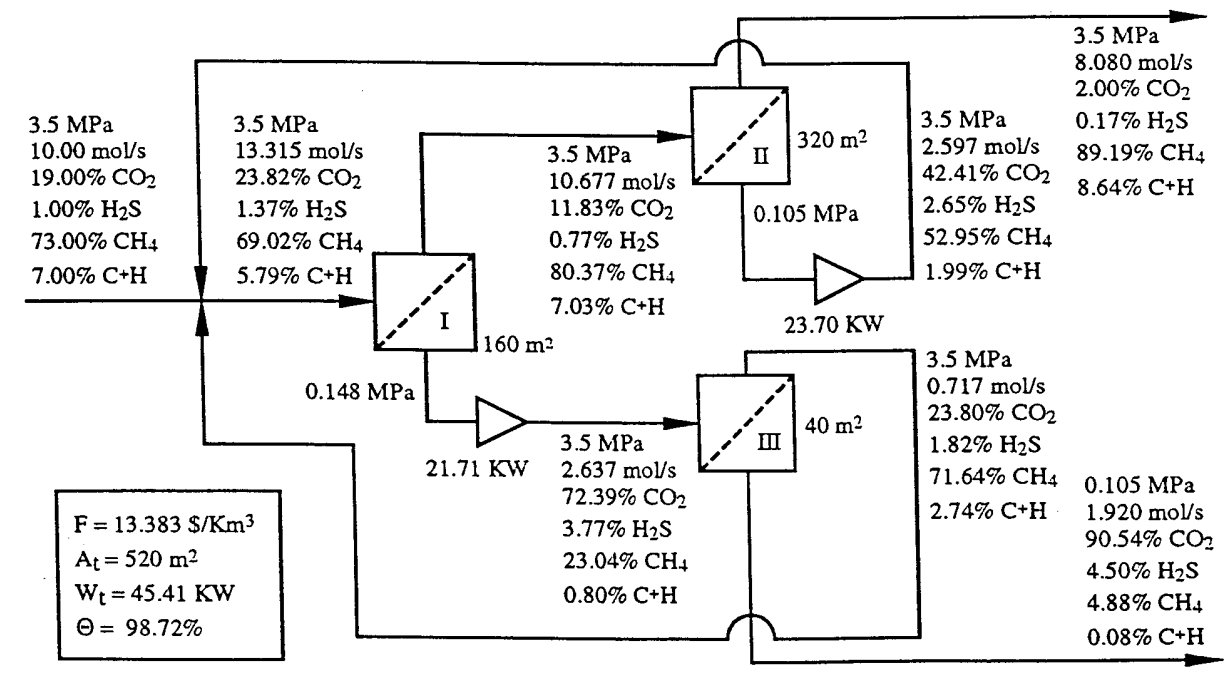

Fig. 7. Three-stage, four-component system with membrane element area of $20 \mathrm{~m}^{2}$ (enhanced oil recovery).

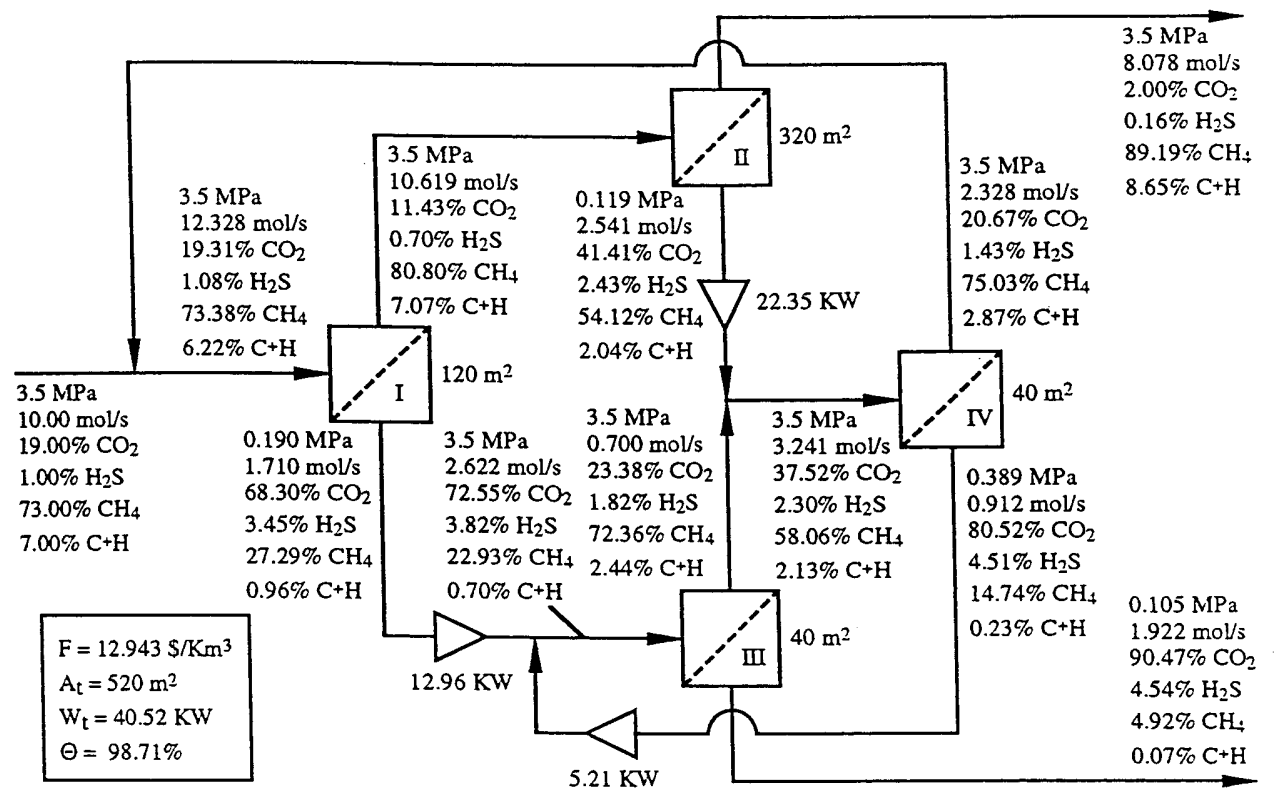

Fig. 8. Four-stage, four-component system with membrane element area of $20 \mathrm{~m}^{2}$ (enhanced oil recovery). 


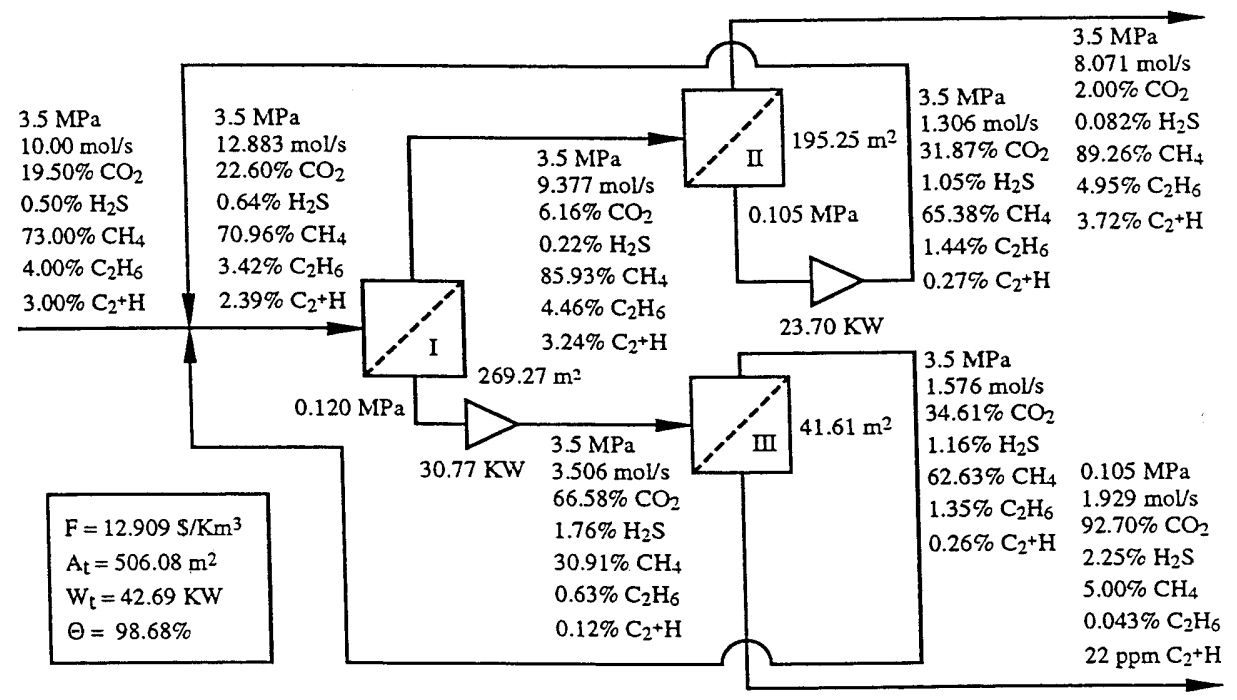

Fig. 9. Three-stage, five-component system with continuous membrane area (enhanced oil recovery).

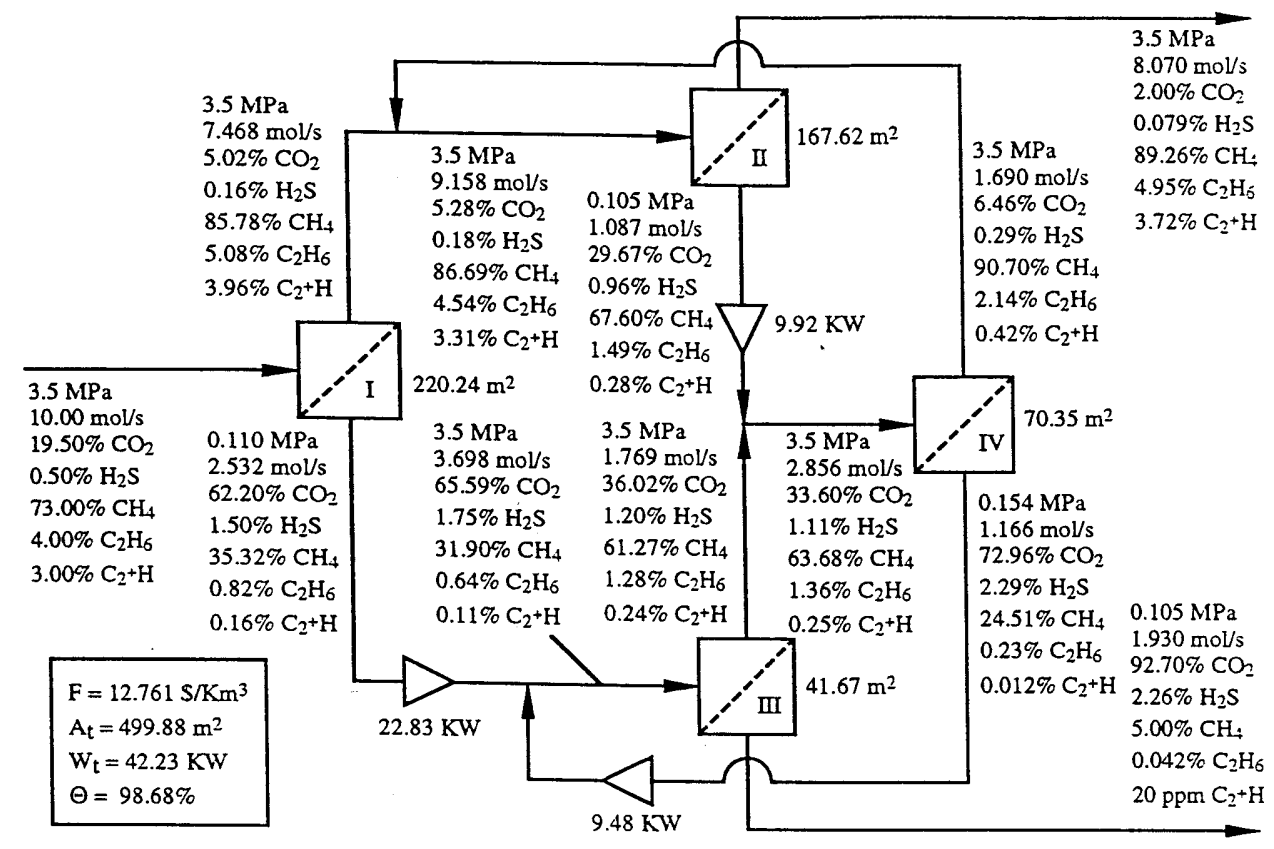

Fig. 10. Four-stage, five-component system with continuous membrane area (enhanced oil recovery).

structure may introduce multiple compressors that could be combined into a single compressor. A modified superstructure is needed to minimize the number of recycle compressors (Agrawal, 1997).

\section{Conclusions}

An optimal design strategy based on an algebraic permeator model and MINLP has been proposed for membrane systems separating multicomponent gas mixtures. The MINLP strategy utilizes a permeator system superstructure to embed a very large number of possi- ble network configurations. The superstructure is formulated as a MINLP model and solved using standard optimization codes to yield the flowsheet that minimizes the annual process cost. Case studies have been presented for spiral-wound permeators separating acid gases $\left(\mathrm{CO}_{2}\right.$ and $\left.\mathrm{H}_{2} \mathrm{~S}\right)$ from crude natural gas mixtures in natural gas treatment and enhanced oil recovery. Optimal designs are derived for different number of membrane stages with both continuous and discrete membrane area. Optimization of the feed-side pressure is also investigated. The results demonstrate that the MINLP strategy is an effective tool for preliminary design of multi-stage, multicomponent gas membrane 
systems, including those with very small component concentrations.

\section{List of symbols}

$\mathscr{A}_{i} \quad$ dimensionless constant defined by Eq. (14)

$A \quad$ membrane area for each stage $\left(\mathrm{m}^{2}\right)$

$A_{\mathrm{t}} \quad$ total membrane area of system $\left(\mathrm{m}^{2}\right)$

$B$ permeability of the spacing material inside the spiral-wound leaf $\left(\mathrm{m}^{2}\right)$

$\mathscr{B}_{i} \quad$ dimensionless constant defined by Eq. (15)

$C$ dimensionless constant defined by Eq. (2)

$C^{\prime \prime} \quad$ permeate-side pressure parameter defined by Eq. (3) $\left(\mathrm{MPa}^{2} \mathrm{~s} / \mathrm{mol}\right)$ $d \quad$ thickness of membrane skin (m)

$d_{\mathrm{m}} \quad$ thickness of membrane leaf $(\mathrm{m})$

$f_{\mathrm{cc}} \quad$ annual capital charge (\%/year)

$f_{\text {cp }} \quad$ capital cost of gas-powered compressors $(\$ /$ KW)

$f_{\mathrm{hv}} \quad$ sales gas gross heating value $\left(\mathrm{MJ} / \mathrm{m}^{3}\right)$

$f_{\mathrm{mh}} \quad$ capital cost of membrane housing $\left(\$ / \mathrm{m}^{2}\right.$ membrane)

$f_{\mathrm{mr}} \quad$ expense of membrane replacement $\left(\$ / \mathrm{m}^{2}\right.$ membrane)

$f_{\mathrm{mt}} \quad$ maintenance rate $(\% /$ year $)$

$f_{\text {sg }} \quad$ utility and sales gas price $\left(\$ / \mathrm{km}^{3}\right)$

$f_{\mathrm{wk}} \quad$ working capital rate $(\%)$

$F \quad$ annual process cost $\left(\$ / \mathrm{km}^{3}\right)$

$F_{\text {cc }} \quad$ annual capital charge $(\$ /$ year $)$

$F_{\text {fc }} \quad$ fixed capital investment (\$)

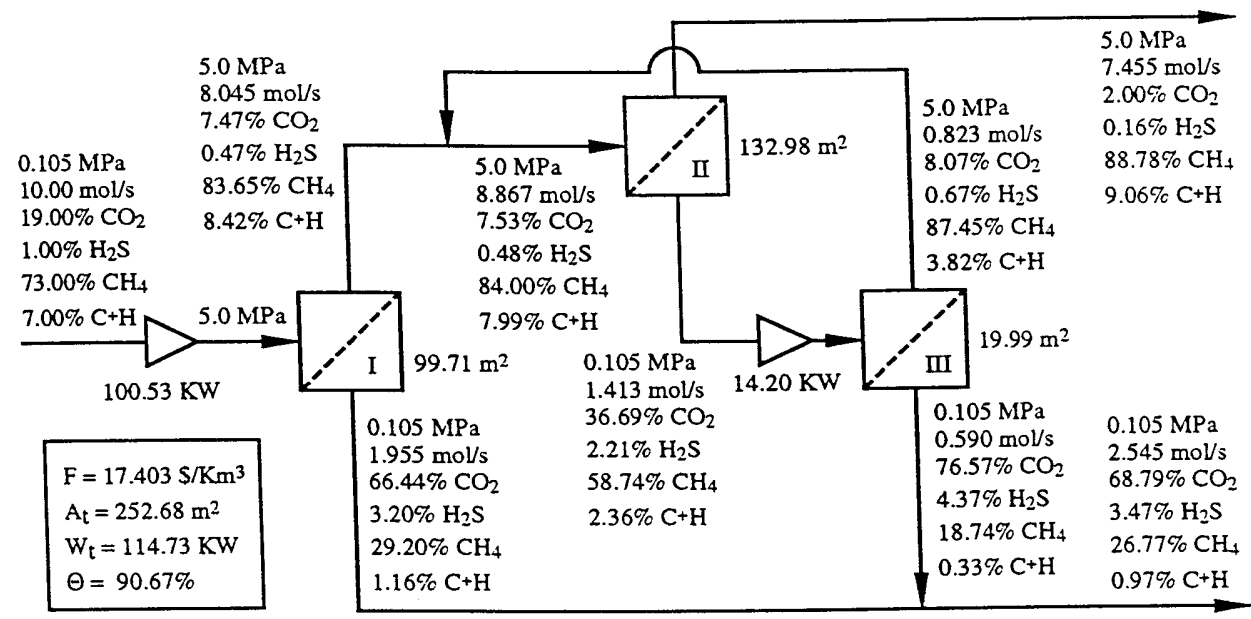

Fig. 11. Feed-side pressure optimization for three-stage, four-component system (natural gas treatment).

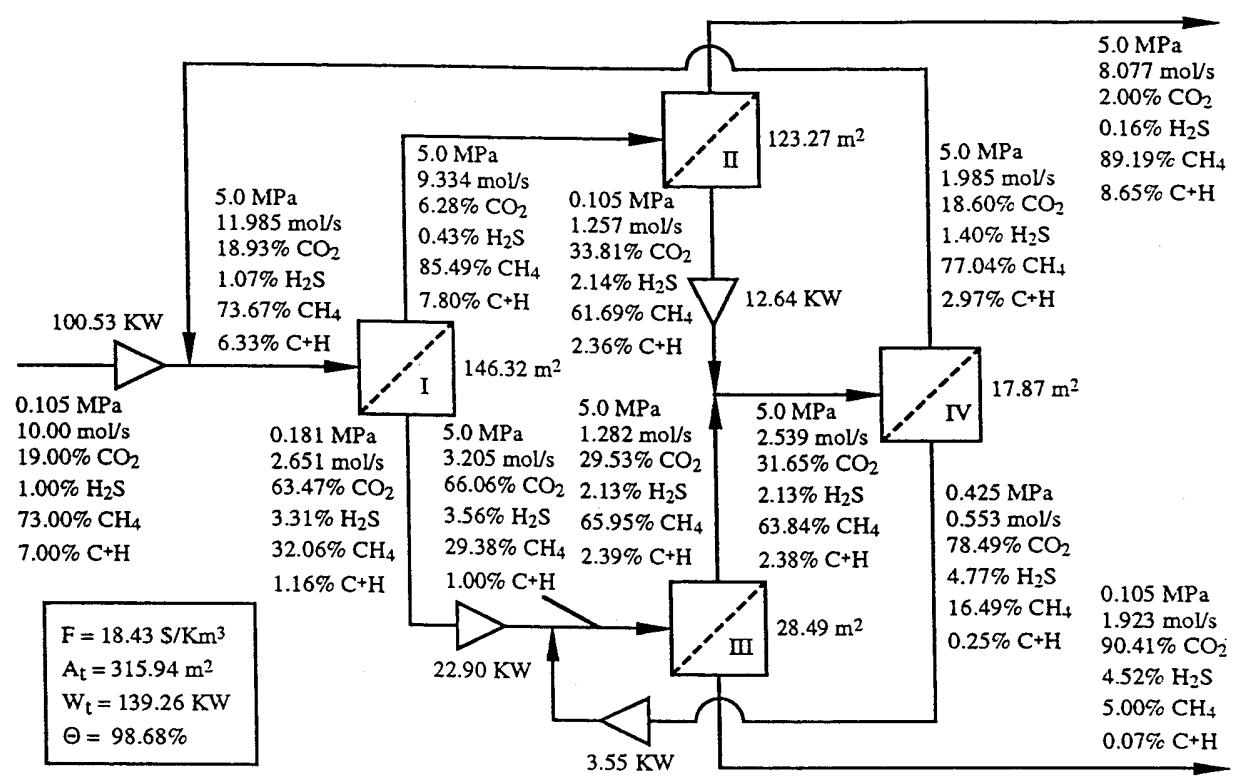

Fig. 12. Feed-side pressure optimization for four-stage, four-component system (enhanced oil recovery). 
$F_{\mathrm{mr}} \quad$ expense of membrane replacement (\$/year)

$F_{\mathrm{mt}} \quad$ maintenance expense (\$/year)

$F_{\mathrm{pl}} \quad$ value of product losses $(\$ /$ year $)$

$F_{\text {ut }} \quad$ Cost of utilities (\$/year)

$\mathscr{F} \quad$ vector function expressed in Eq. (22)

$h \quad$ dimensionless leaf length variable

$K_{1}-K_{4} \quad$ variables defined in Eqs. (17)-(20)

$L \quad$ membrane leaf length (m)

$M \quad$ number of quadrature points

$N_{\mathrm{b}} \quad$ minimum number of binary variables for integer conversion

$N_{\mathrm{c}} \quad$ number of components for gas mixtures

$N_{\text {s }} \quad$ number of permeator stages

$N^{\mathrm{A}} \quad$ number of membrane elements for each stage

$N^{\mathrm{AL}} \quad$ lower bound of membrane element number

$N^{\mathrm{AU}} \quad$ upper bound of membrane element number

$P \quad$ feed-side pressure (MPa)

$P_{\mathrm{f}} \quad$ fresh feed pressure (MPa)

$P^{\mathrm{U}} \quad$ upper bound on feed-side pressure (MPa)

$p \quad$ permeate-side pressure (MPa)

$p_{\text {out }} \quad$ required outlet permeate pressure $(\mathrm{MPa})$

$p_{0} \quad$ permeate outlet pressure for each permeator $(\mathrm{MPa})$

$Q_{i} \quad$ permeability of the $i$ th component $(\mathrm{mol} / \mathrm{m}$ $\mathrm{s} \mathrm{Pa)}$

$Q_{\mathrm{b}} \quad$ permeability of the base component ( $\mathrm{mol} / \mathrm{m}$ $\mathrm{s} \mathrm{Pa)}$

$R$ dimensionless permeation factor defined by Eq. (8)

$R_{\mathrm{g}} \quad$ ideal gas constant $\left(\mathrm{m}^{3} \mathrm{~Pa} / \mathrm{kg} \mathrm{mol} \mathrm{K}\right)$

$S \quad$ slack variable in logic constraints

$t_{\mathrm{m}} \quad$ membrane life (years)

$t_{\mathrm{w} k} \quad$ annual working time (days/year)

$T \quad$ temperature $(\mathrm{K})$

$U_{\mathrm{f}} \quad$ feed flow rate for each permeator $(\mathrm{mol} / \mathrm{s})$

$U_{\mathrm{f} 0} \quad$ fresh feed flow rate for each permeator $(\mathrm{mol} / \mathrm{s})$

$U_{\text {foo }} \quad$ total fresh feed flow rate as processing capacity $(\mathrm{mol} / \mathrm{s})$

$U_{0} \quad$ flow rate of residue gas at permeator outlet $(\mathrm{mol} / \mathrm{s})$

$U_{\mathrm{b}} \quad$ flow rate of residue gas as recycle stream $(\mathrm{mol} / \mathrm{s})$

$U_{\mathrm{p}} \quad$ flow rate of residue gas as product stream $(\mathrm{mol} / \mathrm{s})$

$U_{\mathrm{pt}} \quad$ total flow rate of residue product $(\mathrm{mol} / \mathrm{s})$

$U^{\mathrm{L}} \quad$ upper bound on stream flow rate $(\mathrm{mol} / \mathrm{s})$

$U^{\mathrm{U}} \quad$ lower bound on stream flow rate $(\mathrm{mol} / \mathrm{s})$

$V_{0} \quad$ permeate flow rate at permeator outlet $(\mathrm{mol} / \mathrm{s})$

$V_{\mathrm{b}} \quad$ flow rate of permeate gas as recycle stream $(\mathrm{mol} / \mathrm{s})$

$V_{\mathrm{p}} \quad$ flow rate of permeate gas as product stream $(\mathrm{mol} / \mathrm{s})$

$V_{\mathrm{pt}} \quad$ total flow rate of permeate product $(\mathrm{mol} / \mathrm{s})$
$W \quad$ membrane leaf width (m)

$W_{\text {cp }} \quad$ stage compressor power $(\mathrm{kW})$

$W_{\mathrm{cp}, \mathrm{f}} \quad$ fresh feed compressor power $(\mathrm{kW})$

$W_{\mathrm{t}} \quad$ total compressor power $(\mathrm{kW})$

$w_{j} \quad$ quadrature weights

$x \quad$ local feed-side concentration (mole fraction)

$x_{0} \quad$ bulk residue stream concentration at permeator outlet (mole fraction)

$x_{\mathrm{f}} \quad$ feed concentration for each stage (mole fraction)

$x_{\mathrm{fo}} \quad$ fresh feed concentration (mole fraction)

$x_{\text {out }, \mathrm{CO}_{2}}$ maximum $\mathrm{CO}_{2}$ concentration of residue product (mole fraction)

$x_{\mathrm{pt}} \quad$ concentration of residue product (mole fraction)

$x_{\mathrm{r}} \quad$ local residue concentration along outlet end of membrane leaf (mole fraction)

$Y \quad$ vector defined in Eq. (21)

$y_{0} \quad$ permeate concentration in bulk permeate stream at permeate outlet (mole fraction)

$y_{\mathrm{pt}} \quad$ concentration of permeate product (mole fraction)

$y_{\text {out, } \mathrm{CH}_{4}}$ maximum $\mathrm{CH}_{4}$ concentration of permeate product (mole fraction)

$y^{\prime} \quad$ local permeate concentration on the membrane surface (mole fraction)

$y_{\mathrm{f}}^{\prime} \quad$ local permeate concentration along inlet end of membrane leaf (mole fraction)

$y_{j}^{\prime} \quad$ local permeate concentration at quadrature point $j$ (mole fraction)

$y_{\mathrm{r}}^{\prime} \quad$ local permeate concentration along outlet end of membrane leaf (mole fraction)

$\bar{y}^{\prime} \quad$ composition variable defined by Eq. (8)

$\bar{y}_{\mathrm{f}}^{\prime} \quad \bar{y}^{\prime}$ value at the feed inlet

$\bar{y}_{\mathrm{r}}^{\prime} \quad \bar{y}^{\prime}$ value at the residue outlet

$\bar{y}_{j}^{\prime} \quad \bar{y}^{\prime}$ value at the $j$-th quadrature point

$Z^{\mathrm{A}} \quad$ binary variable used to express discrete membrane area

$Z^{U_{\mathrm{b}}} \quad$ binary variable denoting the existence or nonexistence of $U_{\mathrm{b}}$

$Z^{U_{\mathrm{fo}}} \quad$ binary variable denoting the existence or nonexistence of $U_{\mathrm{f} 0}$

$Z^{U_{\mathrm{p}}} \quad$ binary variable denoting the existence or nonexistence of $U_{\mathrm{p}}$

$Z^{V_{\mathrm{b}}} \quad$ binary variable denoting the existence or nonexistence of $V_{\mathrm{b}}$

$Z^{V_{\mathrm{p}}} \quad$ binary variable denoting the existence or nonexistence of $V_{\mathrm{p}}$

$\alpha_{i} \quad Q_{i} / Q_{\mathrm{b}}$, membrane selectivity for the ith component

$\gamma \quad p / P$, ratio of permeate pressure to feed pressure

$\gamma_{0} \quad p_{0} / P$, ratio of permeate pressure to feed pressure at permeate outlet

viscosity of gas mixture ( $\mathrm{Pa} \mathrm{s}$ ) 
$\theta_{0} \quad V_{0} / U_{\mathrm{f}}$, ratio of permeate flow to feed flow at permeate outlet

$\Theta \quad \mathrm{CH}_{4}$ recovery (\%)

$\xi_{\mathrm{j}} \quad$ quadrature points

$\phi \quad$ dimensionless feed-side flow rate

$\phi_{\mathrm{r}} \quad$ dimensionless feed-side flow rate at residue outlet

$\begin{array}{ll}\eta_{\mathrm{cp}} & \text { compressor efficiency (\%) } \\ \Phi_{i} & \text { function defined by Eqs. (26) and (27) }\end{array}$

$\Phi_{j}^{\prime} \quad$ function defined by Eq. (28)

$\Psi \quad$ function defined by Eq. (29)

\section{Subscripts}

$i \quad$ index of components in gas mixture

$j \quad$ index of quadrature points for the summation term in Eq. (10)

$k \quad$ index of binary variables in expression of discrete membrane area; index of components in gas mixture

$m, n \quad$ index of membrane stages

$q \quad$ index of quadrature points for leaf length variable $h$

\section{Acknowledgements}

Financial support from the National Science Foundation (Grant CTS-9817298) and the LSU Office of Research, as well as technical support from the GAMS Development Corporation, are gratefully acknowledged.

\section{Appendix A. Multicomponent permeator model}

The approximate model is comprised of four groups of nonlinear algebraic equations. The first group contains one equation that describes the permeate-side pressure distribution,

$\gamma^{2}=\gamma_{0}^{2}+\frac{1}{2} C\left(1-\phi_{\mathrm{r}}\right)\left(1-h^{2}\right)$

where $\gamma(h)$ is the ratio of the permeate-side and feedside pressures; $\gamma_{0}$ is $\gamma$ at the permeate outlet; $\phi_{\mathrm{r}}(h)$ is the dimensionless residue gas flow rate; $h$ is the dimensionless membrane leaf length variable; and:

$C \equiv \frac{2 R_{\mathrm{g}} T \mu L U_{\mathrm{f}}}{W d_{\mathrm{m}} B P^{2}}$

The remaining variables are defined in the Section 5 .

The coefficient $C$ can be factored as follows:

$C=C^{\prime \prime} \frac{U_{\mathrm{f}}}{A P^{2}}$ where $U_{\mathrm{f}}$ is the feed gas flow rate, $P$ the feed-side pressure, $A$ the membrane area, and $C^{\prime \prime}$ a parameter that depends on the internal properties of the permeator.

The second group includes three equations that describe the relations between the local feed-side concentration $x_{i}$ and the local permeate-side concentration $y_{i}^{\prime}$ :

$x_{i}=\gamma y_{i}^{\prime}+\frac{(1-\gamma) y_{i}^{\prime}}{\alpha_{i} \bar{y}^{\prime}}, \quad i=1, \ldots, N_{\mathrm{c}}$

$y_{i}^{\prime}=\frac{\alpha_{i} x_{i} \bar{y}^{\prime}}{1-\gamma+\gamma \alpha_{i} \bar{y}^{\prime}}, \quad i=1, \ldots, N_{\mathrm{c}}$

$\sum_{i=1}^{N_{\mathrm{c}}} \frac{\alpha_{i} x_{i} \bar{y}^{\prime}}{1-\gamma+\gamma \alpha_{i} \bar{y}^{\prime}}=1$

where $\alpha_{i}$ is the selectivity of component $i, N_{\mathrm{c}}$ is the number of components, and $\bar{y}^{\prime}$ is a composition variable defined as:

$\bar{y}^{\prime}=\sum_{i=1}^{N_{\mathrm{c}}} \frac{y_{i}^{\prime}}{\alpha_{i}}$

Note that Eqs. (5) and (6) are different forms of the same equation, while Eq. (7) is the summation of Eq. (6) over all components. Different forms are shown to facilitate the subsequent development.

The third group consists of one equation that describes the relation between the dimensionless permeation factor,

$R \equiv \frac{2 W L Q_{\mathrm{b}} P}{d U_{\mathrm{f}}}=A \frac{Q_{\mathrm{b}}}{d} \frac{P}{U_{\mathrm{f}}}$

the composition variable $\bar{y}^{\prime}$, and the dimensionless feedside flow rate $\phi$ :

$R=\frac{1}{1-\gamma}\left(\bar{y}_{\mathrm{f}}^{\prime}-\phi_{\mathrm{r}} \bar{y}_{\mathrm{r}}^{\prime}+\left(\bar{y}_{\mathrm{r}}^{\prime}-\bar{y}_{\mathrm{f}}^{\prime}\right) \sum_{j=1}^{M} \phi_{j} w_{j}\right)$

The summation term is a Gaussian quadrature approximation of a finite integral (Rice \& Do, 1995). The subscripts $\mathrm{f}, \mathrm{r}$, and $j$ represent the permeator properties at the feed inlet, residue outlet, and quadrature point $j$, respectively. $M$ is the number of quadrature points, $w_{j}$ is the quadrature weight at the quadrature point $\xi_{j}$, and:

$\bar{y}_{j}^{\prime}=\bar{y}_{\mathrm{f}}^{\prime}+\xi_{j}\left(\bar{y}_{\mathrm{r}}^{\prime}-\bar{y}_{\mathrm{f}}^{\prime}\right)$

The fourth group of equations describe the relations between the dimensionless permeate-side pressure $\gamma$, the local permeate-side concentration $y_{i}^{\prime}$, and the dimensionless feed-side flow rate $\phi$. The initial-value ordinary different equations are:

$\frac{\mathrm{d}(\ln \phi)}{\mathrm{d} \bar{y}^{\prime}}=-\frac{\sum_{k=1}^{N_{\mathrm{c}}} \mathscr{A}_{k} y_{k}^{\prime}}{\sum_{k=1}^{N_{\mathrm{c}}} \mathscr{B}_{k} y_{k}^{\prime}}$ 
$\frac{\mathrm{d} y_{i}^{\prime}}{\mathrm{d} \bar{y}^{\prime}}=y_{i}^{\prime}\left(\mathscr{A}_{i}-\mathscr{B}_{i} \frac{\sum_{k=1}^{N_{\mathrm{c}}} \mathscr{A}_{k} y_{k}^{\prime}}{\sum_{k=1}^{N_{\mathrm{c}}} \mathscr{B}_{k} y_{k}^{\prime}}\right), \quad i=2, \ldots, N_{\mathrm{c}}$

where:

$\mathscr{A}_{i}=\frac{1-\gamma}{\left(1-\gamma+\gamma \alpha_{i} \bar{y}^{\prime}\right) \bar{y}^{\prime}} \quad i=1, \ldots, N_{\mathrm{c}}$

$\mathscr{B}_{i}=\frac{(1-\gamma)\left(\alpha_{i} \bar{y}^{\prime}-1\right)}{1-\gamma+\gamma \alpha_{i} \bar{y}^{\prime}} \quad i=1, \ldots, N_{\mathrm{c}}$

The initial conditions $\bar{y}^{\prime}=\bar{y}_{\mathrm{f}}^{\prime}, \bar{y}_{i}^{\prime}=\bar{y}_{\mathrm{f}, i}^{\prime}$, and $\phi=\phi_{\mathrm{f}}=1$ are calculated from the second group of Eqs. (5)-(7). Numerical solutions for $\phi$ and $y_{i}^{\prime}$ are obtained using a fourth-order Runge-Kutta-Gill approximation at each quadrature point $\bar{y}_{j}^{\prime}$ and the outlet point $\bar{y}_{r}^{\prime}$. The resulting expressions are (Rice \& Do, 1995):

$Y_{j}=Y_{j-1}+\frac{1}{6}\left(K_{1}+K_{4}\right)+\frac{1}{3}\left(\lambda_{2} K_{2}+\lambda_{4} K_{3}\right)$

$K_{1}=\delta_{j} \cdot \mathscr{F}\left(\bar{y}_{j-1}^{\prime}, Y_{j-1}\right)$

$K_{2}=\delta_{j} \cdot \mathscr{F}\left(\bar{y}_{j-1}^{\prime}+\frac{\delta_{j}}{2}, Y_{j-1}+\frac{1}{2} K_{1}\right)$

$K_{3}=\delta_{j} \cdot \mathscr{F}\left(\bar{y}_{j-1}^{\prime}+\frac{\delta_{j}}{2}, Y_{j-1}+\lambda_{1} K_{1}+\lambda_{2} K_{2}\right)$

$K_{4}=\delta_{j} \cdot \mathscr{F}\left(\bar{y}_{j-1}^{\prime}+\delta_{j}, Y_{j-1}+\lambda_{3} K_{2}+\lambda_{4} K_{3}\right)$

where:

$Y_{j}=\left[\ln \phi_{j}, y_{j, 2}^{\prime}, \ldots, y_{j, N}^{\prime}\right]^{\mathrm{T}}$

$\mathscr{F}=\left[f_{\phi}, f_{2}, \ldots, f_{n}\right]^{\mathrm{T}}$

$\delta_{j}=\bar{y}_{j}^{\prime}-\bar{y}_{j-1}^{\prime}$

$\lambda_{1}=\frac{\sqrt{2}-1}{2}, \quad \lambda_{2}=\frac{2-\sqrt{2}}{2}, \quad \lambda_{3}=-\frac{\sqrt{2}}{2}$,

$$
\lambda_{4}=\frac{2+\sqrt{2}}{2}
$$

The functions $f_{\phi}, f_{2}, \ldots, f_{N_{\mathrm{c}}}$ represent the right-hand sides of Eqs. (12) and (13), and $y_{j, i}^{\prime}$ is the permeate concentration of the $i$ th component at the quadrature point $\bar{y}_{j}^{\prime}$. The initial conditions are:

$Y_{0}=\left[0, y_{\mathrm{f}, 2}^{\prime}, \ldots, y_{\mathrm{f}, N_{\mathrm{c}}}^{\prime}\right]^{\mathrm{T}}$

where $y_{\mathrm{f}, i}^{\prime}$ is determined from $\bar{y}_{f}^{\prime}$ using Eq. (6).

This procedure yields $N_{\mathrm{c}}$ nonlinear algebraic equations that must be solved simultaneously at each quadrature point $j$ and the outlet point to yield $\phi_{j}, y_{j, i}^{\prime}$, $\phi_{\mathrm{r}}$, and $y_{\mathrm{r}, i}^{\prime}$ for $i=2, \ldots, N_{\mathrm{c}}$. Note that these equations are solved for a given value of $\gamma$, and therefore $\bar{y}^{\prime}$ is the only independent variable. When $\gamma$ is a variable, the resulting functions for $\phi_{\mathrm{r}}, y_{\mathrm{r}, i}^{\prime}$ and $\phi_{j}$ can be expressed as:

$$
\begin{aligned}
& \phi_{r}=\Phi_{1}\left(\gamma, \bar{y}_{\mathrm{f}}^{\prime}, \bar{y}_{\mathrm{r}}^{\prime}\right) \\
& y_{\mathrm{r}, i}^{\prime}=\Phi_{i}\left(\gamma, \bar{y}_{\mathrm{f}}^{\prime}, \bar{y}_{\mathrm{r}}^{\prime}\right), \quad i=2, \ldots, N_{\mathrm{c}} \\
& \phi_{j}=\Phi_{j}^{\prime}\left(\gamma, \bar{y}_{\mathrm{f}}^{\prime}, \bar{y}_{\mathrm{r}}^{\prime}\right) \quad j=1, \ldots, M
\end{aligned}
$$

Substitution of $\phi_{\mathrm{r}}$ and $\phi_{j}$ into Eq. (10) yields the relation:

$R=\Psi\left(\gamma, \bar{y}_{\mathrm{f}}^{\prime}, \bar{y}_{\mathrm{r}}^{\prime}\right)$

Simultaneous solution of the nonlinear algebraic Eqs. (2), (7), (26) and (29) at each quadrature point yields $\bar{y}_{\mathrm{f}}^{\prime}\left(h_{q}\right), \gamma\left(h_{q}\right), \phi_{\mathrm{r}}\left(h_{q}\right)$, and $\bar{y}_{\mathrm{r}}^{\prime}\left(h_{q}\right)$, where $h_{q}$ represents the value of $h$ at the $q$ th quadrature point. Substitution of these variables into Eq. (27) yields $y_{\mathrm{r}, i}^{\prime}\left(h_{q}\right)$, which then is used to calculate $x_{\mathrm{r}, i}\left(h_{q}\right)$ via Eq. (5).

The flow rate and concentration of the effluent permeate stream are calculated from integral expressions approximated using Gaussian quadrature. Under most conditions, a single quadrature point at $h_{1}=0.5$ is sufficient. In this case, the resulting equations are (Qi \& Henson, 1996):

$\theta_{0}=1-\phi_{\mathrm{r}}\left(h_{1}\right)$

$y_{0, i}=\frac{x_{\mathrm{f}, i}-x_{\mathrm{r}, i}\left(h_{1}\right) \phi_{\mathrm{r}}\left(h_{1}\right)}{1-\phi_{\mathrm{r}}\left(h_{1}\right)}, \quad i=2, \ldots, N_{\mathrm{c}}$

The flow rate and concentration of the effluent residue stream are determined from an overall material balance about the permeator.

\section{Appendix B. Annual process cost}

The fixed capital investment is the installed equipment cost of membrane vessels and compressors. Note that membrane housing is a capital cost, but the replacement of membrane elements is treated as an operating expense. The cost of membrane housing and replacement are determined by the membrane area. Auxiliary costs associated with pipes, fittings and assembly are included in the membrane housing cost. As a result, the fixed capital investment $\left(F_{\mathrm{fc}}\right)$ is only a function of total membrane area $\left(A_{\mathrm{t}}\right)$ and total compressor power $\left(W_{\mathrm{t}}\right)$ :

$F_{\mathrm{fc}}=f_{\mathrm{mh}} \sum_{n=1}^{N_{\mathrm{s}}} A_{n}+f_{\mathrm{cp}} \frac{W_{\mathrm{t}}}{\eta_{\mathrm{cp}}}$

where $A_{\mathrm{t}}=\Sigma_{n=1}^{N_{\mathrm{s}}} A_{n}$ and $N_{\mathrm{s}}$ is the number of separation stages. The remaining parameters are defined in the Section 5. The total compressor power is the sum of the fresh feed compressor power $\left(W_{\text {cp, }}\right)$ and the compressor power for each stage $\left(W_{\mathrm{cp}, \mathrm{n}}\right)$ :

$W_{\mathrm{t}}=W_{\mathrm{cp}, \mathrm{f}}+\sum_{n=1}^{N_{\mathrm{s}}} W_{\mathrm{cp}, \mathrm{n}}$ 
where compressor power is calculated by assuming ideal gas behavior and isothermal compression (Peters \& Timmerhaus, 1980):

$$
\begin{aligned}
& W_{\mathrm{cp}, \mathrm{f}}=R_{\mathrm{g}} T U_{\mathrm{fo0}} \ln \left(\frac{P}{P_{\mathrm{f}}}\right) \\
& W_{\mathrm{cp}, n}=R_{\mathrm{g}} T\left(\sum_{m=1}^{N_{\mathrm{s}}} V_{\mathrm{b}, m, n}\right) \ln \left(\frac{P}{p_{0, n}}\right), \quad n=1, \ldots, N_{\mathrm{s}}
\end{aligned}
$$

Here $V_{\mathrm{b}, m, n}$ is the permeate recycle stream flow rate from the $n$th stage to $m$ th stage. Note that if the feed-side pressure for each stage is equal to the fresh feed pressure, the fresh feed compressor is eliminated and $W_{\mathrm{cp}, \mathrm{f}}$ becomes zero.

The working capital is taken as fixed percentage $\left(f_{\mathrm{wk}}\right)$ of the fixed capital, and the annual capital charge $\left(F_{\mathrm{cc}}\right)$ is calculated by annualizing the fixed and working capitals:

$F_{\mathrm{cc}}=f_{\mathrm{cc}}\left(1+\mathrm{f}_{\mathrm{wk}}\right) F_{\mathrm{fc}}$

The annual operating costs include:

membrane replacement expense $\left(F_{\mathrm{mr}}\right)$ :

$F_{\mathrm{mr}}=\frac{f_{\mathrm{mr}}}{t_{m}} \sum_{n=1}^{N_{\mathrm{s}}} A_{n}$

maintenance expense $\left(F_{\mathrm{mt}}\right)$ :

$F_{\mathrm{mt}}=f_{\mathrm{mt}} F_{\mathrm{fc}}$

cost of utilities $\left(F_{\mathrm{ut}}\right)$ :

$F_{\mathrm{ut}}=\frac{f_{\mathrm{sg}} t_{\mathrm{wk}}}{f_{\mathrm{hv}} \eta_{\mathrm{cp}}} W_{\mathrm{t}}$

value of product losses $\left(F_{\mathrm{pl}}\right)$ :

$F_{\mathrm{pl}}=f_{\mathrm{sg}} t_{\mathrm{wk}} V_{\mathrm{pt}} \frac{y_{\mathrm{pt}, k}}{x_{\mathrm{pt}, k}}$

The annual process cost $(F)$ is the sum of the capital charge and operating expenses divided by process capacity, which is expressed as:

$F=\frac{\left[F_{\mathrm{cc}}+F_{\mathrm{mr}}+F_{\mathrm{mt}}+F_{\mathrm{ut}}+F_{\mathrm{pl}}\right]}{\left(U_{\mathrm{fo0}} t_{\mathrm{wk}}\right)}$

\section{Appendix C. Constraints}

\section{C.1. Material Balance}

Material balance constraints are imposed on (i) splitters for the initial feed stream and the outlet streams of each stage; (ii) mixers for the inlet streams of each stage and the inlet streams for the final products; and (iii) each permeation stage. For a system with $N$ stages, material balances on the splitters can be expressed as:

$$
\begin{aligned}
U_{\mathrm{fo} 0} & =\sum_{n=1}^{N_{\mathrm{s}}} U_{\mathrm{f} 0, n} \\
U_{0, n} & =U_{\mathrm{p}, n}+\sum_{m=1}^{N_{\mathrm{s}}} U_{\mathrm{b}, m, n}, \quad n=1, \ldots, N_{\mathrm{s}} \\
V_{0, n} & =V_{\mathrm{p}, n}+\sum_{m=1}^{N_{\mathrm{s}}} V_{\mathrm{b}, m, n}, \quad n=1, \ldots, N_{\mathrm{s}}
\end{aligned}
$$

where $U_{\mathrm{foo}}$ is the total fresh feed flow rate; $U_{\mathrm{fo}, n}$ the fresh feed flow rate for stage $n ; U_{0, n}\left(V_{0, n}\right)$ the total outlet residue (permeate) flow rate for stage $n ; U_{\mathrm{p}, n}$ $\left(V_{\mathrm{p}, n}\right)$ is the residue (permeate) flow rate of the final product from stage $n$; and $U_{\mathrm{b}, m, n}\left(V_{\mathrm{b}, m, n}\right)$ is the residue (permeate) flow rate of the recycle stream from the $n$th stage to mth stage. Note that only overall material balances are needed because splitters do not change stream compositions.

For the stream mixers, both overall material balances and component balances are necessary. Material balances for the inlet mixer of stage $n$ are written as:

$$
\begin{gathered}
U_{\mathrm{f}, n}=U_{\mathrm{f} 0, n}+\sum_{m=1}^{N_{\mathrm{s}}}\left(U_{\mathrm{b}, n, m}+V_{\mathrm{b}, n, m}\right), \quad n=1, \ldots, N_{\mathrm{s}} \\
U_{\mathrm{f}, n} x_{\mathrm{f}, n, i}=U_{\mathrm{fo}, n} x_{\mathrm{f} 0, i}+\sum_{m=1}^{N_{\mathrm{s}}}\left(U_{\mathrm{b}, n, m} x_{0, m, i}+V_{\mathrm{b}, n, m} y_{0, m, i}\right), \\
n=1, \ldots, N_{\mathrm{s}} ; i=2, \ldots, N_{\mathrm{c}}
\end{gathered}
$$

The variables are defined in the Section 5 . Note that the recycle streams are taken from the $m$ th stage and terminate at the $n$th stage. Material balances for the product mixers are expressed as:

$$
\begin{aligned}
& U_{\mathrm{pt}}=\sum_{n=1}^{N_{\mathrm{s}}} U_{\mathrm{p}, n} \\
& U_{\mathrm{pt}} x_{\mathrm{pt}, i}=\sum_{n=1}^{N_{\mathrm{s}}} U_{\mathrm{p}, n} x_{0, n, i}, \quad i=2, \ldots, N_{\mathrm{c}} \\
& V_{\mathrm{pt}}=\sum_{n=1}^{N_{\mathrm{s}}} V_{\mathrm{p}, n} \\
& V_{\mathrm{pt}} y_{\mathrm{pt}, i}=\sum_{n=1}^{N_{\mathrm{s}}} V_{\mathrm{p}, n} y_{0, n, i}, \quad i=2, \ldots, N_{\mathrm{c}}
\end{aligned}
$$

where $U_{\mathrm{pt}}$ and $x_{\mathrm{pt}, i}$ are the total flow rate and concentrations of the final residue product, and $V_{\mathrm{pt}}$ and $y_{\mathrm{pt}, i}$ are the total flow rate and concentrations of the final permeate product. Material balances about each permeation stage yield:

$$
\begin{aligned}
& U_{\mathrm{f}, n}=U_{0, n}+V_{0, n}, \quad n=1, \ldots, N_{\mathrm{s}} \\
& U_{\mathrm{f}, n} x_{\mathrm{f}, n, i}=U_{0, n} x_{0, n, i}+V_{0, n} y_{0, n, i}, \quad n=1, \ldots, N_{\mathrm{s}} \\
& i=2, \ldots, N_{\mathrm{c}}
\end{aligned}
$$

\section{C.2. Permeator Model}

The permeator model constraints are comprised of the approximate permeator model equations written for 
each stage. Some of the equations are manipulated to facilitate computer implementation. The following equations are used to define parameters:

$C_{n}=\frac{C^{\prime \prime} U_{\mathrm{f}, n}}{A_{n} P^{2}}, \quad n=1, \ldots, N_{s}$

$R_{n}=\frac{\left(Q_{2} / d\right) A_{n} P}{U_{\mathrm{f}, n}}, \quad n=1, \ldots, N_{s}$

$V_{0, n}=U_{\mathrm{f}, n} \theta_{0, n}, \quad n=1, \ldots, N_{s}$

$p_{0, n}=P \gamma_{0, n}, \quad n=1, \ldots, N_{s}$

The permeate-side pressure distribution is obtained from Eq. (2) using a single quadrature point at $h_{1}=0.5$,

$\gamma_{n}^{2}=\gamma_{0, n}^{2}+0.375 C_{n}\left(1-\phi_{\mathrm{r}, n}\right), \quad n=1, \ldots, N_{\mathrm{s}}$

The relations Eqs. (5) and (7) between the local feedside concentration $x_{i}$ and the local permeate-side concentration $y_{i}^{\prime}$ are needed for both feed and residue ends of the permeator:

$$
\begin{aligned}
& \sum_{i=1}^{N_{\mathrm{c}}} \frac{\alpha_{i} x_{\mathrm{f}, n, i} \bar{y}_{\mathrm{f}, n}^{\prime}}{1-\gamma_{n}+\gamma_{n} \alpha_{i} \bar{y}_{\mathrm{f}, n}^{\prime}}=1, \quad n=1, \ldots, N_{\mathrm{s}} \\
& \sum_{i=1}^{N_{\mathrm{c}}} \frac{\alpha_{i} x_{\mathrm{r}, n, i} \bar{y}_{\mathrm{r}, n}^{\prime}}{1-\gamma_{n}+\gamma_{n} \alpha_{i} \bar{y}_{\mathrm{r}, n}^{\prime}}=1, \quad n=1, \ldots, N_{\mathrm{s}} \\
& x_{\mathrm{f}, n, i}=\gamma_{n} y_{\mathrm{f}, n, i}^{\prime}+\frac{\left(1-\gamma_{n}\right) y_{\mathrm{f}, n, i}^{\prime}}{\alpha_{i} \bar{y}_{\mathrm{f}, n}^{\prime}}, \quad i=1, \ldots, N_{\mathrm{c}} \\
& n=1, \ldots, N_{\mathrm{s}} \\
& x_{\mathrm{r}, n, i}=\gamma_{n} y_{\mathrm{r}, n, i}^{\prime}+\frac{\left(1-\gamma_{n}\right) y_{\mathrm{r}, n, i}^{\prime}}{\alpha_{i} \bar{y}_{\mathrm{r}, n}^{\prime}}, \quad i=1, \ldots, N_{\mathrm{c}} ; \\
& n=1, \ldots, N_{\mathrm{s}}
\end{aligned}
$$

The relation Eq. (10) for the dimensionless permeation factor is written as:

$$
\begin{aligned}
& \left(1-\gamma_{n}\right) R_{n}=\bar{y}_{\mathrm{f}, n}^{\prime}-\phi_{\mathrm{r}, n} \bar{y}_{\mathrm{r}, n}^{\prime}+\left(\bar{y}_{\mathrm{r}, n}^{\prime}-\bar{y}_{\mathrm{f}, n}^{\prime}\right) \sum_{j=1}^{M} \phi_{j, n} w_{j}, \\
& n=1, \ldots, N_{\mathrm{s}}
\end{aligned}
$$

The dimensionless feed-side flow rates $\phi_{j}$ and $\phi_{\mathrm{r}}$ and the local permeate concentration at the residue outlet $y_{\mathrm{r}, i}^{\prime}$ are determined by Runge-Kutta-Gill approximation of initial-value differential equations at each quadrature point $\bar{y}_{j}^{\prime}$ and the residue outlet $\bar{y}_{\mathrm{r}}^{\prime}$. The quadrature and outlet points are determined by the following equation:

$$
\begin{aligned}
& \bar{y}_{j, n}^{\prime}=\bar{y}_{\mathrm{f}, n}^{\prime}+\xi_{j}\left(\bar{y}_{\mathrm{r}, n}^{\prime}-\bar{y}_{\mathrm{f}, n}^{\prime}\right), \\
& \quad j=1, \ldots, M+1 ; n=1, \ldots, N_{\mathrm{s}}
\end{aligned}
$$

in which the last point $(j=M+1)$ represents the residue outlet. The Runge-Kutta-Gill equations Eqs. (16)-(20) are written as:

$$
K_{1, j, n}=\delta_{j, n} \cdot \mathscr{F}\left(\bar{y}_{j-1, n}^{\prime}, Y_{j-1, n}, \gamma_{n}\right)
$$

$$
K_{2, j, n}=\delta_{j, n} \cdot \mathscr{F}\left(\bar{y}_{j-1, n}^{\prime}+\frac{\delta_{j, n}}{2}, Y_{j-1, n}+\frac{1}{2} K_{1, j, n}, \gamma_{n}\right)
$$

$$
\begin{aligned}
& K_{3, j, n}= \\
& \delta_{j, n} \cdot \mathscr{F}\left(\bar{y}_{j-1, n}^{\prime}+\frac{\delta_{j, n}}{2}, Y_{j-1, n}+\lambda_{1} K_{1, j, n}+\lambda_{2} K_{2, j, n}, \gamma_{n}\right)
\end{aligned}
$$

$$
\begin{aligned}
& K_{4, j, n}= \\
& \delta_{j, n} \cdot \mathscr{F}\left(\bar{y}_{j-1, n}^{\prime}+\delta_{j, n}, Y_{j-1, n}+\lambda_{3} K_{2, j, n}+\lambda_{4} K_{3, j, n}, \gamma_{n}\right)
\end{aligned}
$$

$$
Y_{j, n}=Y_{j-1, n}+\frac{1}{6}\left(K_{1, j, n}+K_{4, j, n}\right)+\frac{1}{3}\left(\lambda_{2} K_{2, j, n}+\lambda_{4} K_{3, j, n}\right)
$$

where $j=1, \ldots, M+1 ; n=1, \ldots, N_{\mathrm{s}}$, and $Y$ and $\mathscr{F}$ are defined in Appendix A. Note that $Y$ and $K_{1}-K_{4}$ are vectors with $N_{\mathrm{c}}$ elements, while $\mathscr{F}$ is a $N_{\mathrm{c}}$-element vector function. Thus, $Y_{j, n}$ and $K_{1, j, \mathrm{n}}-K_{4, j, n}$ are three-dimensional arrays. The vector function $\mathscr{F}$ is derived from equations Eqs. (12) and (13) by noting that $y_{i}^{\prime}=$ $Y_{i}$ for $i=2, \ldots, N_{\mathrm{c}}$ and $y_{1}^{\prime}=1-\sum_{i=2}^{N_{\mathrm{c}}} Y_{i}$ :

$$
\begin{aligned}
& \mathscr{F}_{1}\left(\bar{y}^{\prime}, Y, \gamma\right)= \\
& -\frac{\mathscr{A}_{1}\left(\bar{y}^{\prime}, \gamma\right)\left(1-\sum_{i=2}^{N_{\mathrm{c}}} Y_{i}\right)+\sum_{i=2}^{N_{\mathrm{c}}} \mathscr{A}_{i}\left(\bar{y}^{\prime}, \gamma\right) Y_{i}}{\mathscr{B}_{1}\left(\bar{y}^{\prime}, \gamma\right)\left(1-\sum_{i=2}^{N_{\mathrm{c}}} Y_{i}\right)+\sum_{i=2}^{N_{\mathrm{c}}} \mathscr{B}_{i}\left(\bar{y}^{\prime}, \gamma\right) Y_{i}} \\
& \mathscr{F}_{i}\left(\bar{y}^{\prime}, Y, \gamma\right)=Y_{i}\left[\mathscr{A}_{i}\left(\bar{y}^{\prime}, \gamma\right)+\mathscr{B}_{i}\left(\bar{y}^{\prime}, \gamma\right) \mathscr{F}_{1}\left(\bar{y}^{\prime}, Y, \gamma\right)\right], \\
& \quad i=2, \cdots, N_{\mathrm{c}}
\end{aligned}
$$

where $Y_{i}$ is the $i$ th element of the vector $Y$, and the parameters $\mathscr{A}_{i}$ and $\mathscr{B}_{i}$ are defined by equations Eqs. (14) and (15) for each component $i$ :

$$
\begin{aligned}
& \mathscr{A}_{i}\left(\bar{y}^{\prime}, \gamma\right)=\frac{1-\gamma}{\left(1-\gamma+\gamma \alpha_{i} \bar{y}^{\prime}\right) \bar{y}^{\prime}}, \quad i=1, \ldots, N_{\mathrm{c}} \\
& \mathscr{B}_{i}\left(\bar{y}^{\prime}, \gamma\right)=\frac{(1-\gamma)\left(\alpha_{i} \bar{y}^{\prime}-1\right)}{1-\gamma+\gamma \alpha_{i} \bar{y}^{\prime}}, \quad i=1, \ldots, N_{\mathrm{c}}
\end{aligned}
$$

The GAMS environment does not allow redefinition of functions inside the constraint definition. As a result, expressions Eqs. (64)-(68) for the function $\mathscr{F}$ need to be written explicitly. The initial conditions for $Y_{j, n}$ are:

$Y_{0, n}=\left[0, y_{\mathrm{f}, n, 2}^{\prime}, \ldots, y_{\mathrm{f}, n, N_{\mathrm{c}}}^{\prime}\right]^{\mathrm{T}}, \quad n=1, \ldots, N_{\mathrm{s}}$

and the interval $\delta$ is chosen as the difference between $\bar{y}^{\prime}$ at adjacent quadrature points:

$\delta_{j, n}=\bar{y}_{j, n}^{\prime}-\bar{y}_{j-1, n}^{\prime}, \quad j=1, \ldots, M+1 ; n=1, \ldots, N_{\mathrm{s}}$

The local feed-side flow rates $\phi_{j}$ and $\phi_{\mathrm{r}}$ and the local permeate concentration at the residue outlet $y_{r, i}^{\prime}$ are calculated as:

$\phi_{j, n}=\exp \left(Y_{j, n, 1}\right), \quad j=1, \ldots, M ; n=1, \ldots, N_{\mathrm{s}}$ 
$\phi_{\mathrm{r}, n}=\exp \left(Y_{M+1, n, 1}\right), \quad n=1, \ldots, N_{\mathrm{s}}$

$y_{\mathrm{r}, n, i}^{\prime}=Y_{M+1, n, i}, \quad n=1, \ldots, N_{s} ; i=2, \ldots, N_{\mathrm{c}}$

The flow rate and concentration of the effluent permeate stream from each stage are given by Eqs. (30) and (31):

$\theta_{0, n}=1-\phi_{\mathrm{r}, n}, \quad n=1, \ldots, N_{\mathrm{s}}$

$y_{0, n, i}=\frac{x_{\mathrm{f}, n, i}-x_{\mathrm{r}, n, i} \phi_{\mathrm{r}, n}}{1-\phi_{\mathrm{r}, n}}, \quad n=1, \ldots, N_{\mathrm{s}} ; i=2, \ldots, N_{\mathrm{c}}$

The flow rate and concentration of the effluent residue stream are determined by overall material balance equations.

\section{C.3. Composition Sum}

These constraints force the sum of component mole fractions to be unity:

$\sum_{i=1}^{N_{\mathrm{c}}} x_{\mathrm{f}, n, i}=1, \quad n=1, \ldots, N_{\mathrm{s}}$

$\sum_{i=1}^{N_{\mathrm{c}}} y_{\mathrm{f}, n, i}^{\prime}=1, \quad n=1, \ldots, N_{\mathrm{s}}$

$\sum_{i=1}^{N_{\mathrm{c}}} x_{\mathrm{r}, n, i}=1, \quad n=1, \ldots, N_{\mathrm{s}}$

$\sum_{i=1}^{N_{\mathrm{c}}} y_{\mathrm{r}, n, i}^{\prime}=1, \quad n=1, \ldots, N_{\mathrm{s}}$

$\sum_{i=1}^{N_{\mathrm{c}}} x_{0, n, i}=1, \quad n=1, \ldots, N_{\mathrm{s}}$

$\sum_{i=1}^{N_{\mathrm{c}}} y_{0, n, i}=1, \quad n=1, \ldots, N_{\mathrm{s}}$

$\sum_{i=1}^{N_{\mathrm{c}}} x_{\mathrm{pt}, i}=1, \quad n=1, \ldots, N_{\mathrm{s}}$

$\sum_{i=1}^{N_{\mathrm{c}}} y_{\mathrm{pt}, i}=1, \quad n=1, \ldots, N_{\mathrm{s}}$

\section{C.4. Operating Requirement}

Constraints are imposed to ensure the product streams satisfy the separation requirements. In acid gas separations from natural gas mixtures, minimum purity requirements are placed on the $\mathrm{CO}_{2}$ concentration in the final residue product and the $\mathrm{CH}_{4}$ concentration in the permeate product stream. In addition, a constraint which expresses that the permeate pressure for each stage must be at least as high as the pressure of the final permeate stream is required. These constraints are expressed as:

$x_{\mathrm{pt}, \mathrm{CO}_{2}} \leq x_{\text {out }, \mathrm{CO}_{2}}$

$y_{\mathrm{pt}, \mathrm{CH}_{4}} \leq y_{\text {out }, \mathrm{CH}_{4}}$ $p_{0, n} \geq p_{\text {out }}$

Depending on the application, some of the constraints may be relaxed. For example, only Eqs. (88) and (90) are required for natural gas treatment since the $\mathrm{CO}_{2}$ enriched permeate stream has little or no value.

\section{C.5. Logic}

Logic constraints are placed on binary variables associated with the existence or nonexistence of various interconnections. The first type of logic constraint forces the flow rate to be zero if the associated connection is not utilized $(Z=0)$. If the connection is utilized $(Z=1)$, the corresponding constraint is relaxed to allow the flow rate to assume any value up to an upper bound $\left(U^{\mathrm{U}}\right)$. These logic relations for the feed, product, and recycle streams are expressed as follows:

$$
\begin{aligned}
& U_{\mathrm{f} 0, n}-U^{\mathrm{U}} Z_{n}^{\mathrm{Uf0}} \leq 0, \quad n=1, \ldots, N_{\mathrm{s}} \\
& U_{\mathrm{p}, n}-U^{\mathrm{U}} Z_{n}^{\mathrm{U}_{\mathrm{p}}} \leq 0, \quad n=1, \ldots, N_{\mathrm{s}} \\
& V_{\mathrm{p}, n}-U^{\mathrm{U}} Z_{n}^{\mathrm{v}_{\mathrm{p}}} \leq 0, \quad n=1, \ldots, N_{\mathrm{s}} \\
& U_{\mathrm{b}, m, n}-U^{\mathrm{U}} Z_{m, n}^{\mathrm{U}_{\mathrm{b}}} \leq 0, \quad m=1, \ldots, N_{s} ; n=1, \ldots, N_{\mathrm{s}} \\
& V_{\mathrm{b}, m, n}-U^{\mathrm{U}} Z_{m, n}^{\mathrm{V}_{\mathrm{b}}} \leq 0, \quad m=1, \ldots, N_{\mathrm{s}} ; n=1, \ldots, N_{\mathrm{s}}
\end{aligned}
$$

The second type of logic constraint forces the binary variable to be zero if the associated flow rate becomes zero. If the connection is utilized, the corresponding flow rate can assume any value greater than a lower bound $\left(U^{\mathrm{L}}\right)$. These logic relations are expressed as:

$$
\begin{aligned}
& U_{\mathrm{f} 0, n}-U^{\mathrm{L}} Z_{n}^{\mathrm{Uf0}} \leq 0, \quad n=1, \ldots, N_{\mathrm{s}} \\
& U_{\mathrm{p}, n}-U^{\mathrm{L}} Z_{n}^{\mathrm{U}_{\mathrm{p}}} \leq 0, \quad n=1, \ldots, N_{\mathrm{s}} \\
& V_{\mathrm{p}, n}-U^{\mathrm{L}} Z_{n}^{\mathrm{V}_{\mathrm{p}}} \leq 0, \quad n=1, \ldots, N_{\mathrm{s}} \\
& U_{\mathrm{b}, m, n}-U^{\mathrm{L}} Z_{m, n}^{\mathrm{U}_{\mathrm{b}}} \leq 0, \quad m=1, \ldots, N_{s} ; n=1, \ldots, N_{\mathrm{s}} \\
& V_{\mathrm{b}, m, n}-U^{\mathrm{L}} Z_{m, n}^{\mathrm{V}_{\mathrm{b}}} \leq 0, \quad m=1, \ldots, N_{\mathrm{s}} ; n=1, \ldots, N_{\mathrm{s}}
\end{aligned}
$$

In practice, $U^{\mathrm{L}}$ is a small positive value that is chosen as the minimum flow rate allowed in the system.

The final type of logic constraint is associated with the outlet permeate pressure for each stage. If the outlet permeate stream goes to final product stream mixer, the permeate pressure must equal the product pressure. If the permeate stream is recycled to another stage, the permeate pressure can assume any value less than or equal to the upper limit of the feed-side pressure $P^{\mathrm{U}}$. By introducing a slack variable $S$, these logic relations can expressed as:

$p_{0, n}=S_{n}+p_{\text {out }}, \quad n=1, \ldots, N_{\mathrm{s}}$ 
$0 \leq S_{\mathrm{n}} \leq\left(P^{\mathrm{U}}-p_{\text {out }}\right)\left(1-Z_{n}^{\mathrm{V}_{\mathrm{p}}}\right), \quad n=1, \ldots, N_{\mathrm{s}}$

Note that if $Z_{n}^{V_{\mathrm{p}}}=1$, then $S_{\mathrm{n}}=0$ and $p_{0, \mathrm{n}}=p_{\text {out }}$; if $Z_{n}^{V_{\mathrm{p}}}=0$, then $0 \leq S_{n} \leq P^{\mathrm{U}}-p_{\text {out }}$ and $p_{\text {out }} \leq p_{0, \mathrm{n}} \leq P^{\mathrm{U}}$.

\section{C.6. Discrete Membrane Area}

A typical spiral-wound permeator is comprised of several membrane elements placed in a cylindrical steel shell. A permeator shell normally is capable of holding from one to six spiral-wound membrane elements. Membrane area is adjusted by changing the number of elements or by connecting several permeators in series or parallel. As a result, membrane area may be considered as a discrete variable:

$A_{n}=A_{0} N_{n}^{\mathrm{A}}, \quad n=1, \ldots, N_{\mathrm{s}}$

where $A_{0}$ is the element membrane area size and $N^{\mathrm{A}}$ $\left(N^{\mathrm{AL}} \leq N^{\mathrm{A}} \leq N^{\mathrm{AU}}\right)$ is the number of elements. Because integer variables cannot be handled directly by existing MINLP algorithms, the element number $N^{\mathrm{A}}$ must be expressed in terms of binary variables. One way to convert the integer variables $N^{\mathrm{A}}$ to binary variables $Z^{\mathrm{A}}$ is to use the following expression (Floudas, 1995):

$N_{n}^{\mathrm{A}}=N_{n}^{\mathrm{AL}}+\sum_{k=1}^{N_{\mathrm{b}}} 2^{k-1} Z_{n, k}^{\mathrm{A}}, \quad n=1, \ldots, N_{\mathrm{s}}$

where $N_{\mathrm{b}}$ is the minimum number of binary variable needed:

$N_{\mathrm{b}}=1+\operatorname{int}\left\{\frac{\log \left(N^{\mathrm{AU}}-N^{\mathrm{AL}}\right)}{\log (2)}\right\}$

Note that Eq. (105) is used only to calculate the value of $N_{\mathrm{b}}$; it is not used as a constraint equation. In the following case studies, we choose $N^{\mathrm{AL}}=1$ and $N^{\mathrm{AU}}=$ 15 to 30 , which yield $N_{\mathrm{b}}=4$ or 5 . When the membrane area is regarded as a continuous variable, the constraints Eqs. (103) and (104) are not utilized.

\section{C.7. Nonnegativity and Integrality}

These constraints are used to specify lower and upper variable bounds to prevent undefined operations (e.g. division by zero) and to ensure the variables remain in a reasonable solution space. Proper selection of these bounds is very important for efficient solution of mixed-integer nonlinear models. These constraints are expressed as follows:

$0 \leq U_{\mathrm{fo}, n}, U_{\mathrm{f}, n}, U_{0, n}, V_{0, n}, U_{\mathrm{p}, n}, V_{\mathrm{p}, n}, U_{\mathrm{b}, m, n}, V_{\mathrm{b}, m, n}$,

$U_{\mathrm{pt}}, V_{\mathrm{pt}} \leq U^{\mathrm{U}}$

$A_{n}, N_{n}^{\mathrm{A}}, R_{n}, C_{n}, P, p_{n}, \bar{y}_{\mathrm{f}, n}, \bar{y}_{\mathrm{r}, n}, \bar{y}_{j, n}^{\prime} \geq 0$

$0 \leq x_{\mathrm{f}, n, i}, x_{0, n, i}, y_{0, n, i}, y_{\mathrm{f}, n, i}^{\prime}, y_{j, n, i}^{\prime}, y_{\mathrm{r}, n, i}^{\prime}, x_{\mathrm{r}, n, i}, x_{\mathrm{pt}, i}, y_{\mathrm{pt}, i} \leq 1$

$0 \leq \theta_{0, n}, \gamma_{0, n}, \gamma_{n}, \phi_{\mathrm{r}, n}, \phi_{j, n} \leq 1$

$$
\begin{aligned}
& Z_{n}^{\mathrm{Uf0}}, Z_{n}^{\mathrm{U}_{\mathrm{p}}}, Z_{n}^{\mathrm{V}_{\mathrm{p}}}, Z_{m, n}^{\mathrm{U}_{\mathrm{b}}}, Z_{m, n}^{\mathrm{V}_{\mathrm{b}}}, Z_{n, k}^{\mathrm{A}}=0,1 \\
& m=1, \ldots, N_{\mathrm{s}} ; n=1, \ldots, N_{\mathrm{s}} ; j=1, \ldots, M ; \\
& i=1, \ldots, N_{\mathrm{c}} ; k=1, \ldots, N_{\mathrm{b}}
\end{aligned}
$$

\section{References}

Adjiman, C. S., Androulakis, I. P., \& Floudas, C. A. (1997). Global optimization of MINLP problems in process synthesis and design. Computers and Chemical Engineering, 21, S445-S450.

Agrawal, R. (1997). A simplified method for synthesis of gas separation membrane cascades with limited numbers of compressors. Chemical Engineering Science, 52, 1029-1044.

Agrawal, R., \& Xu, J. (1996a). Gas separation membrane cascades. II. Two compressor cascades. Journal of Membrane Science, 112, 129.

Agrawal, R., \& Xu, J. (1996b). Gas separation membrane cascades utilizing limited numbers of compressors. American Institute of Chemical Engineering Journal, 42, 2141-2154.

Babcock, R. E., Spillman, R. W., Goddin, C. S., \& Cooley, T. E. (1988). Natural gas cleanup: a comparison of membrane and amine treatment processes. Energy Progress, 8, 135-142.

Bhide, B. D., \& Stern, S. A. (1991a). A new evaluation of membrane processes for the oxygen-enrichment of air. I. Identification of optimum operating conditions and process configuration. Journal of Membrane Science, 62, 13-35.

Bhide, B. D., \& Stern, S. A. (1991b). A new evaluation of membrane processes for the oxygen-enrichment of air. II. Effect of economic parameters and membrane properties. Journal of Membrane Science, $81,37-58$.

Bhide, B. D., \& Stern, S. A. (1993a). Membrane processes for the removal of acid gases from natural gas. I. Process configuration and optimization of operating conditions. Journal of Membrane Science, 81, 209-237.

Bhide, B. D., \& Stern, S. A. (1993b). Membrane processes for the removal of acid gases from natural gas. II. Effect of operating conditions, economic parameters, and membrane properties. Journal of Membrane Science, 81, 239-252.

Bhide, B. D., Voskericyan, A., \& Stern, S. A. (1998). Hybrid processes for the removal of acid gases from natural gas. Journal of Membrane Science, 140, 27-49.

Brooke, A., Kendrick, D., \& Meeraus, A. (1992). GAMS: a user's guide. Palo Alto, CA: Scientific Press.

Ettouney, H. M., Al-Enezi, G., \& Hughes, R. (1995). Modelling of enrichment of natural gas wells by membranes. Gas Separation and Purification, 9, 3-11.

Floudas, C. A. (1995). Nonlinear and mixed-integer optimization. Oxford: Scientific Press.

Floudas, C. A., \& Grossmann, I. E. (1994). Algorithmic approaches to process synthesis: logic and global optimization. In Proceedings of the Foundations of Computer-Aided Design (FOCAD '94), (pp. 198-221). Snowmass, CO.

Grossmann, I. E., \& Daichendt, M. M. (1996). New trends in optimization-based approaches to process synthesis. Computers and Chemical Engineering, 20, 665-683.

Grossmann, I. E., \& Kravanja, Z. (1995). Mixed-integer nonlinear programming techniques for process systems engineering. Computers and Chemical Engineering, 19, S189-S204.

Lee, A. L., \& Feldkirchner, H. L. (1993). Development of a database for advanced processes to remove carbon dioxide from subquality natural gas. Topical Report GRI-93/0247, Gas Research Institute.

Lee, A. L., Feldkirchner, H. L., Stern, S. A., Houde, A. Y., Gamez, J. P., \& Meyer, H. S. (1995). Field tests of membrane modules for the separation of carbon dioxide for low-quality natural gas. Gas Separation and Purification, 9, 35-43. 
Pan, C. Y. (1986). Gas separation by high-flux, asymmetric hollowfiber membrane. American Institute of Chemical Engineering Journal, 32, 2020-2027.

Peters, M. S., \& Timmerhaus, K. D. (1980). Plant design and economics for chemical engineers. New York: McGraw-Hill.

Qi, R., \& Henson, M. A. (1996). Approximate modeling of spiralwound gas permeators. Journal of Membrane Science, 121, 1124.

Qi, R., \& Henson, M. A. (1997). Modeling of spiral-wound gas permeators for multicomponent gas separations. Industrial Engineering and Chemical Research, 36, 2320-2331.

Qi, R., \& Henson, M. A. (1998a). Optimal design of spiral-wound membrane networks for gas separations. Journal of Membrane Science, 148, 71-89.

Qi, R., \& Henson, M. A. (1998b). Optimization-based design of spiral-wound membrane systems for $\mathrm{CO}_{2} / \mathrm{CH}_{4}$ separations. Separation and Purification Technique, 13, 209-225.

Quesada, I., \& Grossmann, I. E. (1992). A LP/NLP based branch and bound algorithm for convex MINLP optimization problems. Computers and Chemical Engineering, 16, 937-947.

Rice, R. G., \& Do, D. D. (1995). Applied mathematics and modeling for chemical engineers. New York, NY: Wiley.

Spillman, R. W., Barrett, M. G., \& Cooley, T. E. (1988). Gas membrane process optimization. In American Institute of Chemical Engineers National Meeting, New Orleans, LA.

Srinivas, B. K., \& El-Halwagi, M. M. (1993). Optimal design of pervaporation systems for waste reduction. Computers and Chemical Engineering, 17, 957-970.

Viswanathan, J., \& Grossmann, I. E. (1990). A combined penalty function and outer-approximation method for MINLP optimization. Computers and Chemical Engineering, 14, 769-782.

Xu, J., \& Agrawal, R. (1996). Gas separation membrane cascades. I. One compressor cascades with minimal energy losses due to mixing. Journal of Membrane Science, 112, 115.

Zhu, M., El-Halwagi, M. M., \& Al-Ahmad, M. (1997). Optimal design and scheduling of flexible reverse osmosis networks. Journal of Membrane Science, 129, 161-174. 